\title{
The temporal interpretation of clause chaining in Northern Paiute*
}

\author{
Maziar Toosarvandani \\ University of California, Santa Cruz
}

August 15, 2014

\begin{abstract}
Northern Paiute uses clause chaining to express temporal relations between clauses, which in English are conveyed by the temporal subordinators after and while. But rather than a subordination structure, I show that clause chaining in Northern Paiute has an underlying coordination structure. I propose that the temporal relations between clauses in a chain arise in part through the compositional interaction of coordination and verbal morphology that conveys relative tense. Because Northern Paiute lacks absolute tense, this can be abstracted over in a coordination structure, just as in an embedded clause in other languages (Ogihara 1994, 1995, 1996). In narratives, this semantics is enriched, I argue, by additional interpretive principles for sentences in discourse, which produce a 'forward moving' temporal interpretation (Kamp and Rohrer 1983, Partee 1984, Hinrichs 1986). This in-depth investigation of one language raises questions about the syntax and semantics of clause chaining in other languages.
\end{abstract}

Languages have a variety of grammatical resources for conveying information about time, including tense, temporal adverbials, and temporal adjunct clauses. Northern Paiute - a Uto-Aztecan language of the Numic branch spoken in the western United States - frequently uses a different device. In CLAUSE CHAINING, two or more clauses convey that some events take place, roughly

*I am greatly indebted to Grace Dick, Edith McCann, and Madeline Stevens for continuing to teach me about their language over the years. I thank Pranav Anand, Adrian Brasoveanu, Amy Rose Deal, Donka Farkas, Andrew Garrett, Line Mikkelsen, Sarah Murray, David Pesetsky, Anna Szabolcsi, and Tim Thornes for their insightful questions and comments. In addition, I have learned a lot from audience members at the 2012 and 2013 Linguistic Society of America Annual Meetings in Portland and Boston and at the 18th Workshop on the Structure and Constituency of Languages of the Americas at the University of California, Berkeley, as well as at Rice University, Stony Brook University, the Massachusetts Institute of Technology, the University of California (Los Angeles, Santa Cruz, and San Diego). Tim Thornes very kindly shared a number of his unpublished texts from the Burns variety of Northern Paiute (cited as Thornes, p.c.). Early work on this project was carried out with Timothy Ho, who compiled raw data and formulated some of the basic generalizations.

The fieldwork for this paper was supported by a Jacobs Research Fund Grant (Whatcom Museum Foundation, Bellingham, Washington), Phillips Fund Grant (American Philosophical Society, Philadelphia), and a Grant in Great Basin Studies from the Sven and Astrid Liljeblad Endowment Fund (University of Nevada, Reno). This research was also assisted by a New Faculty Fellowship from the American Council of Learned Societies, funded by the Andrew W. Mellon Foundation. 
speaking, at the same time or in a temporal sequence, depending on whether the suffix -na (1/a) or the suffix - si $(1 \mathrm{p})$ is present. ${ }^{1}$

\author{
a. Yaisi $\mathrm{o}=$ woetsimmi-na, yaisi $\mathrm{o}=$ ggwidzi-na, \\ PTC 3SG.ACC=watch-SIM PTC 3SG.ACC=stir-SIM \\ $\mathrm{o}=$ ddza-puni-hu-dzaga-ti. \\ 3SG.ACC=IP.fingers-see-PFV-MOT-TI
}

'While you are watching it, while you are stirring it, you look at it every once and a while.' (dialogue, MS, BP09-1-t4, 7)

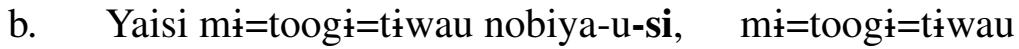

PTC $\mathrm{PL}=\mathrm{dog}=$ also pack-PFV-SEQ $\mathrm{PL}=\mathrm{dog}=\mathrm{also}$

tsa-hibi-ki-u-ga-si, tammi mia-ga-kwi mii.

IP.fingers-drink-APPL-PFV-MOT-SEQ 1PL.INCL.NOM go-MOT-IRR QUOT

'So then, having packed up the dogs, and having made sure those dogs get a drink, so we'd take off.' (narrative, Nepa Kennedy, 'Root-Digging Time', Thornes, p.c.)

The clauses that contain one of these suffixes, which I will refer to as MARKED CLAUSES, cannot stand on their own. In contrast, the final clause in each example above, which I will call the UNMARKED CLAUSE, is inflected like an independent sentence. ${ }^{2}$

\footnotetext{
${ }^{1}$ The data in this paper comes primarily from my own fieldwork on the variety of Northern Paiute spoken at Mono Lake in eastern California (Lee Vining, California) and immediately to the north in Bridgeport and Coleville, California and Sweetwater, Nevada. In addition to the Mono Lake dialect, there are several other closely related dialects spoken across, and immediately adjacent to, the Great Basin. These dialects are all mutually intelligible; the variation amongst them is primarily phonological and lexical (see Babel, Houser, and Toosarvandani 2012 and Babel, Garrett, Houser, and Toosarvandani 2013 for details). To a lesser extent, I have also drawn on data from the Burns, Oregon variety (Thornes 2003).

Northern Paiute is severely endangered. For all dialects, there are probably no more than 300 fluent speakers today (Golla 2011:174). For the Mono Lake dialect specifically, there are around five speakers, with varying levels of proficiency. The fieldwork data I present here comes entirely from the two oldest, most fluent speakers of the Mono Lake variety. At the time of writing, Edith McCann was 89 years old and Madeline Stevens was 93 years old. They learned Northern Paiute as their first language and were introduced to English when they started school. Both trace their ancestry to Bridgeport, though they also have family from Mono Lake (Lee Vining) and Sweetwater. There are only a few differences in their speech; these consist entirely of very small lexical differences that reflect minor historical variation amongst the communities in the Mono Lake dialect area (e.g. tiba'a 'pinenut' in Lee Vining, but tiba elsewhere).

Examples from other sources receive the usual parenthetical citation. Examples from my own fieldwork are annotated with relevant metadata: (i) how the data was collected: in a dialogue, through elicitation, in a narrative, or in a prompted narrative, (ii) the initials of the speaker who uttered the example or provided a judgement for the example (EM or MS), (iii) a number (starting with BP) identifying the source recording for the example, and (iii) the example's location in the source recording (either a line number in the corresponding transcription of the recording or a timestamp). The source recordings and transcriptions are not currently available to the public, at the request of the speakers, because they contain culturally sensitive content.

I use the following abbreviations in this paper: $\mathrm{ACC}=$ accusative, APPL $=$ applicative, $\mathrm{DEM}=$ demonstrative, DIM $=$ diminutive, $\mathrm{DL}=$ dual, $\mathrm{EMPH}=$ emphatic particle, $\mathrm{EXCL}=$ exclusive, $\mathrm{GEN}=$ genitive, $\mathrm{IMPF}=$ imperfective, INCEP $=$ inceptive, $\mathrm{INCL}=$ inclusive, $\mathrm{INT}=$ intensive, $\mathrm{IP}=$ instrumental prefix, $\mathrm{IRR}=$ irrealis, $\mathrm{LOC}=$ locatival postposition, $\mathrm{MOD}=$ modal particle, $\mathrm{MOT}=$ motion suffix, $\mathrm{NEG}=$ negation, $\mathrm{NOM}=$ nominative, $\mathrm{NSP}=$ nonspecific patient, PASS $=$ passive, $\mathrm{PFV}=$ perfective, $\mathrm{PL}=$ plural, $\mathrm{PRF}=$ perfect, $\mathrm{PROG}=$ progressive, $\mathrm{PTC}=$ discourse particle, $\mathrm{Q}=$ question particle, $\mathrm{QUOT}=$ quotative, $\mathrm{REFL}=$ possessive anaphor, $\mathrm{SEQ}=$ sequential suffix, $\mathrm{SG}=$ singular, $\mathrm{SIM}=$ simultaneous suffix, STAT $=$ stative, $\mathrm{TI}=$ 'general tense' (see Section 2).

${ }^{2}$ These are sometimes called 'medial' and 'final' clauses, respectively (Longacre 2007:399). While this might
} 
In many languages, these relations between clauses - temporal simultaneity and sequence are conveyed by temporal subordinators, like while and after in English. They create subordination structures that, at least on the surface, look strikingly similar to clause chaining in Northern Paiute.

(2) a. While the senators were debating the motion, they drank tea.

b. After Ben won the race, he collapsed with exhaustion.

The temporal adjunct clauses either temporally include $(2 \mathrm{a})$ or precede $(2 \mathrm{~b})$ the main clause. In addition, while the main clause in each example can stand on its own as an independent sentence, the clauses introduced by the temporal subordinator can only be adjoined.

Despite this surface resemblance, however, there is a persistent intuition in the literature that the clauses in a chain stand in a looser relation to one another — "like beads on a string," in Foley]'s (2010:27) words - one that is more characteristic of coordination. Indeed, as I will show later in Section 1, clause chaining in Northern Paiute has a coordination structure.

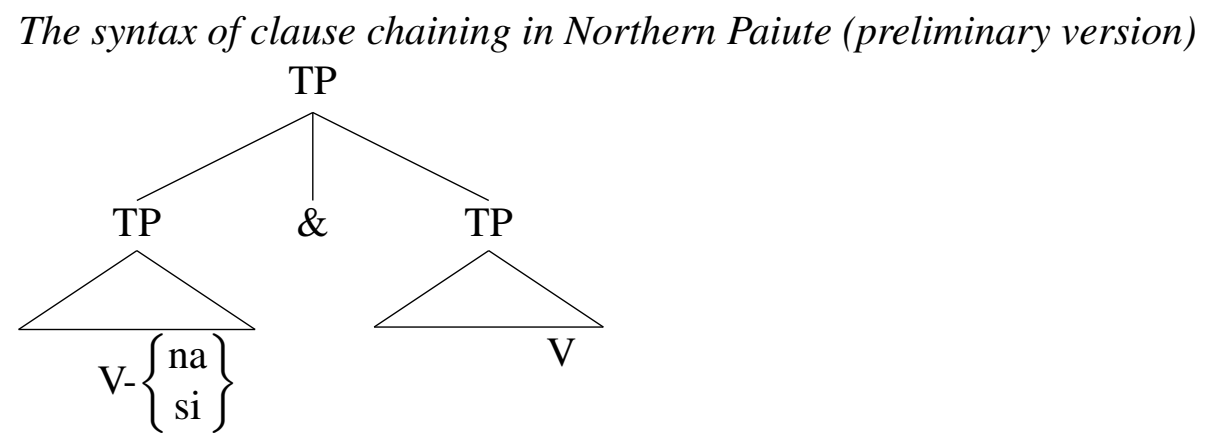

If clause chaining in Northern Paiute has this coordination structure, how does it convey the same temporal relations between clauses that temporal subordinators do?

The answer to this question lies, I believe, in an unexplained property of the coordination structure in 3 . On its face, it violates the conventional wisdom that only 'likes' can be coordinated (see, for example, Huddleston and Pullum 2002:1323-1326). The first coordinate contains the SIMULTANEOUS SUFFIX - $n a$ or the SEQUENTIAL SUFFIX - si, neither of which can occur in the second coordinate. I am not alone in proposing that clause chaining can have a coordination structure - see Roberts 1988 on Amele, Foley 2010 on various Papuan languages, and Nonato 2013 on Kisêdjê. But these authors have either not remarked on this asymmetry or they have left it unexplained.

I argue in Section 2 that the asymmetry of the coordination structure in 3 is only apparent. The simultaneous and sequential suffixes realize the $\mathrm{T}$ (ense) head inside the marked clause, while in the unmarked clause it is simply not pronounced. In terms of their meaning, I propose that the simultaneous and sequential suffixes convey relative tenses (Comrie 1985:56-64). This kind of analysis is considered briefly by Foley (2010:44f.) for different Papuan languages, but he does not show how the semantics of relative tense gives rise to the temporal interpretation of clause chaining.

In Section 3, I propose that the simultaneous and sequential suffixes combine with coordination in a compositional fashion to produce the entailments for clause chaining. Because Northern Paiute lacks absolute tense, the relative tense expressed by one of the suffixes in a marked clause is

seem an accurate characterization of the clause chains in $1 \mathrm{a}-\mathrm{b}$, the terms adopted in the text are more appropriate for Northern Paiute. The linear order of the marked and unmarked clauses is variable — see Section 1.3 . 
abstracted over, just as in an embedded clause in languages like Japanese (Ogihara 1994, 1995, 1996). For each marked clause in a chain, this entails a relation of temporal inclusion or temporal precedence between it and the unmarked clause. This account, which relies on semantic binding, derives the insensitivity of these temporal relations to the linear order of the marked and unmarked clauses.

In Northern Paiute, the marked clauses in a chain are also related temporally to one another, though this is not by an entailment. I argue in Section 4 that this meaning arises from principles that provide a temporal interpretation for sentences in discourse. In narratives, the clauses in a chain receive the same 'forward moving' interpretation that a sequence of independent sentences does (Kamp and Rohrer 1983, Partee 1984, Hinrichs 1986). This additional meaning component, which I formalize using Muskens (1995) logic of change, is sensitive to the linear order of clauses in a chain, capturing Foley's intuition that they resemble "beads on a string."

It is difficult to determine whether this syntax and semantics for clause chaining in Northern Paiute extends to other languages. With some exceptions, the existing literature consists largely of typological surveys (e.g. Longacre 2007) and comparative work on geographically or genetically related languages (e.g. Foley 2010), or it deals with clause chaining only in connection with another topic (e.g. Finer 1985, Roberts 1988, Broadwell 1997). Right now, it is thus not possible to compare Northern Paiute to other languages in any really substantive way. But I hope that this in-depth investigation of one language will raise questions about others, leading in the end to a richer theory of clause chaining.

\section{The syntax of clause chaining in Northern Paiute}

Clause chaining has a remarkably uniform surface profile across languages. In his typological survey, Longacre (2007:398-417) identifies two core properties. First, as he puts it (p. 399), one clause "has a verb of distinctive structure that occurs but once in the entire chain, while the other clauses have verbs of different and more restricted structures." In Northern Paiute, as we have already seen, there is one unmarked clause, which is accompanied by one or more marked clauses. Second, the temporal relations between clauses are marked by morphology signaling a distinction between either (i) temporal simultaneity or (ii) temporal sequence (p. 400). In Northern Paiute, these relations are conveyed by verbal morphology: the simultaneous suffix -na and the sequential suffix - si.

In addition, Longacre observes (p. 399) that clause chaining frequently marks switch reference - that is, whether the subject of one clause is the same as or different from the subject of the following clause. As far as I know, Northern Paiute never realizes switch reference formally (see also Thornes 2003:277f.). But there is no reason to think that this is a necessary property of clause chaining. Switch reference marking shows up whenever clauses are combined, including in unequivocal coordination structures and in different kinds of subordination structures (see the discussion in McKenzie 2012:79-91).

Going beyond this surface description, I propose that clause chaining in Northern Paiute has the coordination structure below. 


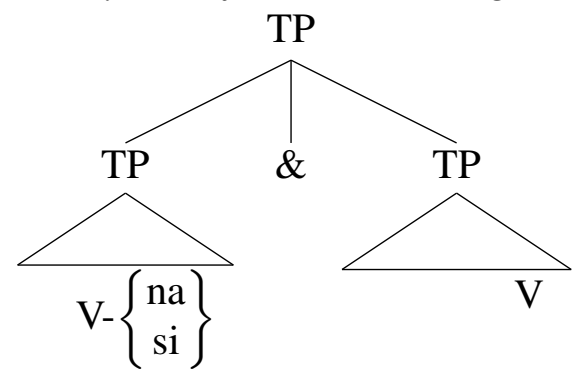

Two or more full clauses, which I assume are TPs, are combined in an asyndetic coordination structure by a phonologically null coordinator. While these clauses are headed by $\mathrm{T}(\mathrm{ense})$, this label does not necessarily have any semantic import.

In some languages, clause chaining is analyzed as subordination (Finer 1985, Broadwell 1997, 2006). But as I show in Section 1.1, questions and left peripheral operators, such as modal clitics and negation, do not treat the marked clause as contained within the unmarked clause in Northern Paiute. In other languages, clause chaining is analyzed as coordination, but at the level of the verb phrase (Foley 2010, Nonato 2013). I argue in Section 1.2 that clause chaining in Northern Paiute must coordinate full clauses. Each member of a chain can contain the same left peripheral elements. Finally, in Section 1.3, I consider the possibility that the simultaneous and sequential suffixes are themselves coordinators. I conclude, however, that they must be contained within the marked clause, since they can be moved with it and select for its contents.

\subsection{Clause chains are not subordinated}

The primary subordination strategy in Northern Paiute is nominalization (see also Thornes 2003:427447). One nominalizer, the suffix $-n a$, derives patient nominalizations (5) ), object relative clauses $(5 \mathrm{~b})$, and the complements of perception verbs (5c) (Toosarvandani 2011, to appear).

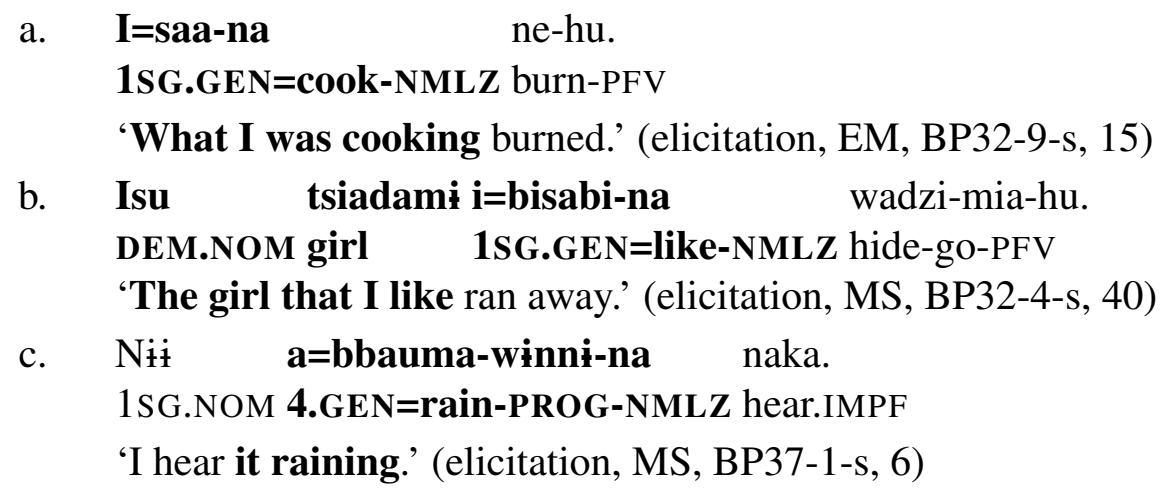

Is it possible that the simultaneous suffix is simply the nominalizer in $5 \mathrm{a}-\mathrm{c}$ ? I doubt that this is so, in part becuase it is in complementary distribution with the sequential suffix, which cannot plausibly be analyzed as a nominalizer. The sequential suffix does not occur on a verb in argument position (6), in a relative clause (6b), or on the complement of a perception verb (6) $)$.

$$
\begin{aligned}
\text { a. } & * \text { I=saa-si } \quad \text { ne-hu. } \\
& \text { 1SG.GEN=cook-SEQ burn-PFV } \\
& \text { (elicitation, EM, BP47-10, 46:49) }
\end{aligned}
$$




$$
\begin{array}{ll}
\text { b. } & \text { Isu tsiadami i=bisabi-si } \quad \text { wadzi-mia-hu. } \\
& \text { DEM.NOM girl 1SG.GEN=like-SEQ hide-go-PFV } \\
& \text { (elicitation, EM, BP50-2, 1:10:00) } \\
\text { c. * } & \text { Nii a a=bbauma-winni-si naka. } \\
& \text { 1SG.NOM 4.GEN=rain-PROG-SEQ hear.IMPF } \\
& \text { (elicitation, EM, BP47-10, 46:13) }
\end{array}
$$

In the Appendix, I provide three additional arguments that the simultaneous suffix is syntactically distinct from the homophonous nominalizer suffix.

Even if the marked clause is not a nominalization, it could be subordinated to the unmarked clause, much like a temporal adjunct clause in English.

The syntax of clause chaining in Northern Paiute (first alternative)

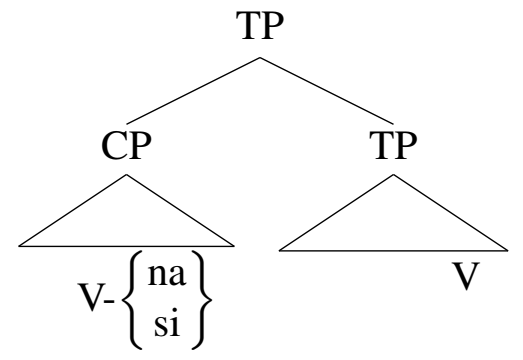

The marked clause would have to be adjoined quite high — to the entire unmarked clause - since it precedes everything in the unmarked clause. This means that the coordination structure in 4 and this alternative subordination structure end up being quite difficult to distinguish syntactically from each other. In neither does an expression in the marked clause c-command into the unmarked clause, or vice versa.

Based on a survey of several North American languages, Finer (1985) assumes a subordination structure like 7 for clause chaining, though he does not provide any arguments for it. For clause chaining in Choctaw specifically, Broadwell (1997, 2006) adopts this subordination structure in part because the marked clause does not appear to contain tense. Regardless of its merit, this argument is not relevant for Northern Paiute, since the language lacks ABSOLUTE TENSE (Comrie 1985:36) - it does not mark the relation between the time at which a clause is interpreted and the utterance time (see also Thornes 2003:396). I offer three other arguments that clause chaining in Northern Paiute has a coordination structure, and not the subordination structure in 7 .

\section{Across-the-board wh-movement}

Across-the-board extraction is permitted in coordination structures $(8 \mathrm{a})$, but it is ungrammatical in subordination structures $(8 \mathrm{~b})$.

a. What ${ }_{1}$ did the nurse polish $\mathbf{t}_{1}$, and the plumber play $\mathbf{t}_{1}$ ?

b. * Who ${ }_{1}$ did Max tell $\mathbf{t}_{1}$ after he saw $\mathbf{t}_{1}$ ?

In Northern Paiute, wh-movement can take place in an across-the-board fashion from each clause in a chain. 
a. Himma ${ }_{1}$ nì $\quad \mathbf{t}_{1}$ tika-na, yaisi su=naatsi' $i=b \dot{i}$ no'o $\mathbf{t}_{1}$ tika?

what 1SG.NOM eat-SIM PTC NOM=boy=PTC eat.IMPF

'What, while I eat it, does the boy eat, too?' (cf. What 1 do I eat $t_{1}$, and the boy eats $t_{1}$, too?) (elicitation, EM, BP39-2-s, 24)

b. Haga ${ }_{1}$ su=tiitsi-'yu naatsi'i $\mathbf{t}_{1}$ mutuhe-hu-si, su=nana=bino'o $\mathbf{t}_{1}$ mutuhe-hu? who NOM=little-NOM boy kiss-PFV-SEQ NOM=man=PTC kiss-PFV

'Who, after the little boy kissed them, did the man kiss, too?' (cf. Who ${ }_{1}$ did the little boy kiss $t_{1}$, and the man kissed $t_{1}$ ?) (elicitation, EM, BP43-4-s, 4)

If clause chaining had the alternative subordination structure, $9 \mathrm{a}-\mathrm{b}$ should be ungrammatical, since wh-movement would cross an adjunct island boundary. Instead, clause chaining in Northern Paiute must have a coordination structure.

\section{Asymmetrical wh-movement}

While extraction is not possible from an adjoined clause, it is possible from the main clause. A whphrase, for instance, can raise to either follow (10 $)$ or precede $(10 \mathrm{p})$ a temporal adjunct clause. In the first case, the clause plausibly adjoins to $\mathrm{C}^{\prime}$, while in the second case it adjoins slightly higher to $\mathrm{CP}$

(10) a. What ${ }_{1}$, when he was studying for his exam, did John drink $\mathbf{t}_{1}$ ?

b. When he was studying for his exam, what ${ }_{1}$ did John drink $\mathbf{t}_{1}$ ?

If the marked clause were adjoined to the unmarked clause, as in the alternative subordination structure in 7, it should exhibit the same extraction pattern. But it is not possible for a wh-phrase to move across the marked clause.

a. * Haga ${ }_{1}$ su=miitsi-'yu nana tiba tika-na, su=tittsi-'yu naatsi'i=bino’o who NOM=short-NOM man pinenut eat-SIM NOM=little-NOM boy=PTC

$\mathbf{t}_{1}$ mutuhe'e?

kiss.IMPF

Intended: 'Who, while the short man was eating pinenuts, did the little boy kiss?' (cf. *Who $o_{1}$ was the short man eating pinenuts, and the little boy kissed $t_{1}$ ?) (elicitation, EM, BP48-3, 52:50)

b. * Haga ${ }_{1}$ su=miitsi-'yu nana ti=nodiggwa puni-si, yaisi su=naatsi'i $\mathbf{t}_{1}$ punni? who NOM=short-NOM man REFL=wife see-SEQ PTC NOM=boy see.IMPF Intended: 'Who, after the short man saw his wife, did the boy see?' (cf. *Who did the short man see his wife, and the boy saw $t_{1}$ ?) (elicitation, EM, BP48-10, 16:08)

This pattern of extraction does, however, follow from the coordination structure for clause chaining in 4 that I am proposing. In $11 \mathrm{a}-\mathrm{b}$, the wh-phrase has been extracted asymmetrically from the second coordinate, violating the Coordinate Structure Constraint (Ross 1967:161).

\footnotetext{
${ }^{3}$ The orthographic commas in $10 \mathrm{a}$ belie that the temporal adjunct clause is fully integrated into the sentence. The characteristic intonation of a parenthetical is missing.
} 
Interestingly, it is possible to question a constituent inside the marked clause. (This is completely ruled out from a temporal adjunct clause: i.e. *What ${ }_{1}$ when he was studying for $t_{1}$, did John drink?)

a. Haga ${ }_{1}$ su=tiłtsi-' yu nana $\mathbf{t}_{1}$ mutuhe-na, yaisi su=naatsi' $i=$ bino'o tiba who NOM=little-NOM man kiss-SIM PTC NOM=boy=PTC pinenut tika?

eat.IMPF

'Who is the little man kissing while the boy is eating pinenuts?' (cf. *Who 1 is the little man kissing $t_{1}$, and the boy is eating pinenuts?) (elicitation, MS, BP48-3-s, 13)

b. Haga ${ }_{1}$ su=miitsi-'yu nana $\mathbf{t}_{1}$ puni-si, yaisi su=naatsi'i tí=bbia who NOM=short-NOM man see-SEQ PTC NOM=boy REFL=mother punni?

see.IMPF

'Who did the short man see, before the boy saw his mother?' (cf. *Who $o_{1}$ did the short man see $t_{1}$, and the boy saw his mother?) (elicitation, EM, BP48-10, 17:13)

At first glance, this might seem problematic for a coordination structure. The wh-phrase in $12 \mathrm{a}-\mathrm{b}$ appears to raise out of just the first coordinate in violation of the Coordinate Structure Constraint.

There is good reason to think, though, that the wh-phrase does not actually leave the first coordinate. While Northern Paiute has wh-movement to a clause initial position (13a), it is not obligatory (13b).
a. Haga ${ }_{1} \mathrm{su}=$ mogo'ni $_{1}$ pisapi?
who NOM=woman like.IMPF
'Who does the woman like?' (elicitation, EM, BP44-7, 7:25)
b. $\quad$ Su=mogo'ni haga pisapi?
NOM=woman who like.IMPF
'Who does the woman like?' (elicitation, EM, BP44-7-s, 5)

This suggests that the wh-phrase in $12 \mathrm{a}-\mathrm{b}$ might just raise into the left periphery of the first coordinate. Question semantics would be contributed by an operator taking scope over both clauses in the chain 4

\footnotetext{
${ }^{4}$ This operator is phonologically null in wh-question, but the question particle hau appears in polar questions. It can take scope over an entire clause chain.

(i) Context: I come into the house. I hear stomping and singing coming from another room.

Hau su=tiitsi-'yu naatsi'i hubiadu-na, yaisi u=bbiia=bino'o nika?

Q NOM=little-NOM boy sing-SIM PTC 3SG.GEN=friend=PTC dance.IMPF

'Was the little boy's friend dancing while he was singing?' (elicitation, EM, BP50-1, s, 2)

(ii) Context: I come into the barn, and I don't see the cow.

Hau su=paba-'yu kutsu wadzi-mia-hu-si, su=naatsi'i u=ggwati-hu?

Q NOM=big-NOM cow hide-go-PFV-SEQ NOM=boy 3SG.ACC=shoot-PFV

'Did the boy shoot the cow after it escaped?' (elicitation, EM, BP49-3-s, 1)
} 
(14)

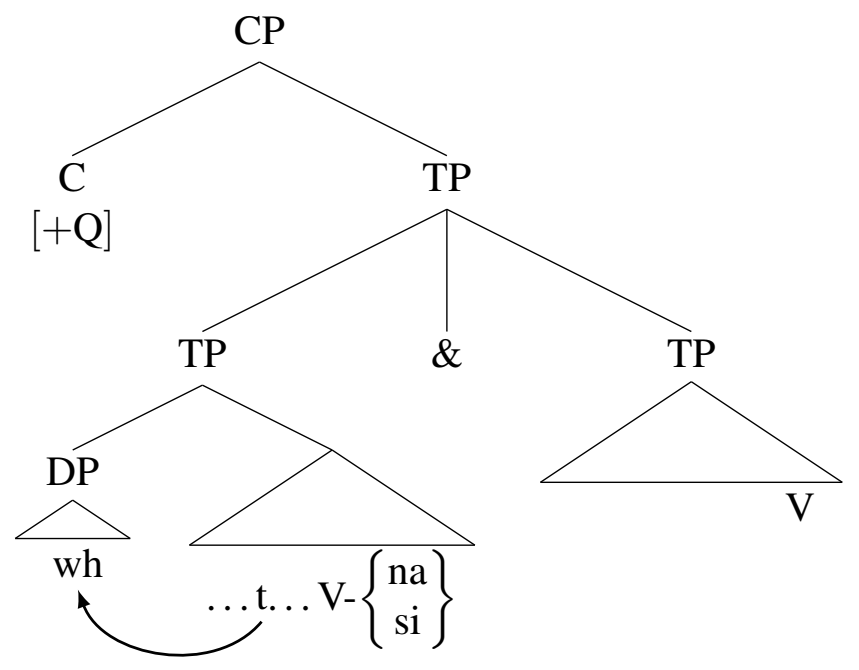

It should be possible, then, also to question a constituent inside the unmarked clause, as long as it does not leave that clause. Indeed, this is the case.

a. Su=miitsi-'yu nana iwi-na, yaisi hanno ${ }_{1}$ su=naatsi'i $\mathbf{t}_{1}$ mia-hu?
NOM=short-NOM man sleep-SIM PTC where NOM=man go-PFV

'While the short man was sleeping, where did the boy go?' (elicitation, EM, BP492-s, 1)

b. Miitsi-'yu nana ya'e-si, hanno 1 su=naatsi'i $\mathbf{t}_{1}$ mia-hu?

short-NOM man die-SEQ where NOM=boy go-PFV

'After the short man died, where did the boy go?' (elicitation, EM, BP49-2-s, 4)

I conclude, then, that clause chaining in Northern Paiute has a coordination structure, because it does not permit asymmetrical wh-movement from just one clause.

\section{Modal clitics}

Another argument that clause chaining in Northern Paiute does not have the alternative subordination structure comes from second position clitics. The language has several clitics that express modality and occur after the first major sentence constituent (Thornes|2003:336-341).
a. $\dot{i}=$ sakwa pida.
2SG.NOM=MOD start.fire
'You should start the fire.' (elicitation, EM, BP33-5-s, 47)
b. Himma=sakwa tammi madabbui.
thing=MOD 1PL.INCL make
'We might make something.' (elicitation, EM, BP34-2-s, 17)
c. Mu'a=sakwa tammi tiba'a hani-gaa-kwi.
tomorrow=MOD 1PL.INCL pinenut do-MOT-IRR
'Tomorrow, we are going to go get pinenuts.' (elicitation, EM, BP33-5-s, 51)

The contexts in if ii establish that the speaker does not know whether either clause in the chain is true. This makes it felicitous for the question particle to take wide scope. 
The modal clitic $=s a k w a$, for instance, can occur after the subject $(16 \mathrm{a})$, a fronted direct object (16), or a sentence initial adverb (16c).

If the marked clause were adjoined in clause initial position, then a modal clitic should immediately follow the marked clause in second position. Instead, it shows up after the first constituent inside the unmarked clause.

a. Su=miitsi-'yu mogo'ni pida-na, su=naatsi' $i=$ sakwa kutsu patsa. NOM=short-NOM woman make.fire-SIM NOM=boy=MOD cow kill

'While the short woman is starting a fire, the boy should kill a cow.' (elicitation, EM, BP50-4, 16:25)

b. Su=paba-'yu kutsu na-dza'maggwi-hu-si, su=naatsi' $i=$ sakwa u=ggwati. NOM=big-NOM cow PASS-let.go-PFV-SEQ NOM=boy=MOD 3SG.ACC=shoot 'After the big cow is let go, and the boy should shoot it.' (elicitation, EM, BP50-4, 12:05)

Since the marked clause does not count as the first element in a sentence for modal clitics, clause chaining in Northern Paiute must instead have a coordination structure.

\subsection{Clause chaining coordinates full clauses}

Based on the three arguments above, I conclude that clause chaining in Northern Paiute does not have a subordination structure. This is the same conclusion that others have come to for various Papuan languages. But in these languages, the marked clause does not contain functional categories found in independent sentences, such as absolute tense, illocutionary force, and negation (Foley and Van Valin 1984:256-263). For this reason, Foley (2010) proposes that in clause chaining subclausal constituents are coordinated under a single T head (see also Nonato 2013).

The syntax of clause chaining in Northern Paiute (second alternative)

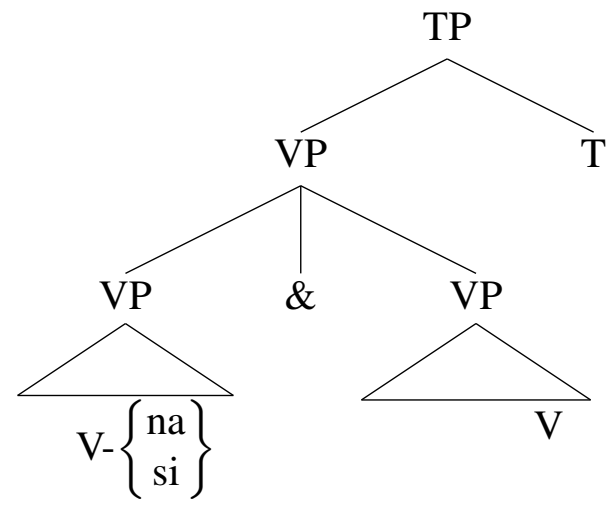

As I will argue below, the alternative low coordination structure in 18 is not appropriate for Northern Paiute. The language does not overtly mark absolute tense, so instead I use negation and modal particles to show that clause chaining coordinates full clauses.

\section{Negation}

In Northern Paiute, negation appears either in sentence initial position (19a) or following the subject at the left edge of the verb phrase (19p) (Thornes 2003:328). 
a. Kai nimmi wiupui-gga yaa.

'We have no buckberries this time.' (dialogue, MS, BP23-1-t1, 3)

b. $\quad \mathrm{Su}=$ natizuabi kai togi i=ma-nimma.

NOM=medicine NEG correct $1 \mathrm{SG} . \mathrm{ACC}=\mathrm{IP}$.hand-feel

'The medicine doesn't make me feel quite right.' (elicitation, Thornes 2003:328)

Assuming that negation adjoins either to $\mathrm{TP}$ or to $\mathrm{vP}$ - the two positions where it is attested crosslinguistically (Laka 1990:9-85) — it can be used to probe the structure of clause chaining.

Under the alternative low coordination structure, high negation should be impossible inside the unmarked clause because it would be just a VP. But this is, in fact, possible.

a. Su=tiitsi-'yu naatsi'i iwi-na, kai su=mogo'ni mia-hu.

NOM=little-NOM boy sleep-SIM NEG NOM=woman go-PFV

'While the little boy was sleeping, the woman didn't leave.' (elicitation, EM, BP50-

4, 17:46)

b. Su=paba-'yu kutsu wadzi-mia-hu-si, yaisi kai su=naatsi'i

NOM=big-NOM cow hide-go-PFV-SEQ PTC NEG NOM=boy

$\mathrm{u}=$ ggwati-hu.

3SG.ACC $=$ shoot-PFV

'After the cow escaped, the boy didn't shoot it.' (elicitation, EM, BP50-4, 26:18)

High negation should not be possible inside the marked clause either, though showing this is a bit more involved. It is clear that the negative particle kai can occur in sentence initial position.

a. Kai su=tiitsi-'yu naatsi'i hubiadu-na, su=mogo'ni mia-hu.

NEG NOM=little-NOM boy sing-SIM NOM=woman go-PFV

'While the little boy wasn't singing, the woman left.' (elicitation, EM, BP50-7, 31:42)

b. Kai su=kutsu wadzi-mia-hu-si, su=naatsi'i u=ggwati-hu.

NEG NOM=cow hide-go-PFV-SEQ NOM=boy 3SG.ACC=shoot-PFV

'After the cow didn't escape, the boy shot it.' (elicitation, EM, BP50-7, 26:57)

If these clause chains had the alternative low coordination structure, high negation should only be able to take scope over the entire coordination. But as the translations in $21 \mathrm{a}-\mathrm{b}$ indicate, it can take scope just inside the marked clause. This is exactly what we would expect if clause chaining in Northern Paiute coordinates full clauses.

\section{Modal clitics}

Recall from Section 1.1 that modal clitics occur in second position in Northern Paiute. I assume this means they occupy $\mathrm{C}$, like the highest auxiliary or main verb in a verb-second Germanic language (Koster 1975, among others). If clause chaining had the alternative low coordination structure, a modal clitic, such as =sakwa, should not be possible inside the unmarked clause. But as we saw in $17 \mathrm{a}-\mathrm{b}$ above, this is indeed possible. 
It is unclear whether the alternative low coordination structure should also permit a modal clitic inside the marked clause. It depends on whether a modal clitic can be interpreted inside the first VP coordinate but surface in $\mathrm{C}$ of the matrix clause. This is, at any rate, possible.
a. Su=miitsi-'yu mogo'ni=sakwa pida-na, su=naatsi'i yaisi kutsu patsa. NOM=short-NOM woman=MOD make.fire-SIM NOM=boy PTC cow kill

'The short woman should start a fire, so the boy will kill a cow.' (elicitation, EM, BP48-6, 17:45)

b. Su=paba-'yu kutsu=sakwa na-dza'ma'wi-hu-si, yaisi su=tiitsi-'yu NOM=big-NOM cow=MOD PASS-let.go-PFV-SEQ PTC NOM=little-NOM naatsi'i u=ggwati-hu.

boy 3SG.ACC=shoot-PFV

'The cow should be let go, so that the boy can shoot him.' (elicitation, EM, BP48$3-s, 16)$

The distribution of modal clitics in 17 and 22 is exactly what we expect if clause chaining in Northern Paiute coordinates full clauses. While I have been assuming for simplicity that these are TPs, there is no reason they could not also be CPs. Then, there would be a position for modal clitics inside both the marked and unmarked clause.

\subsection{Clause chaining is asyndetically coordinated}

Northern Paiute does not have overt coordinators, so clause chaining would have to employ asyndetic coordination. Unless, that is, the simultaneous and sequential suffixes were themselves coordinators. They would be terminal nodes in the syntax, but they would attach phonologically to the element on their left.

\section{The syntax of clause chaining in Northern Paiute (third alternative)}

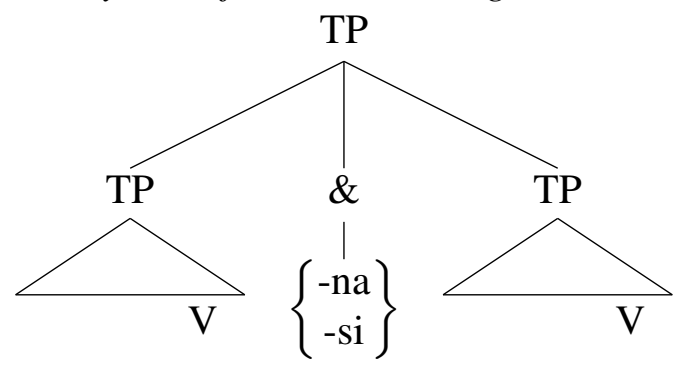

This alternative structure would make the coordination symmetrical. The marked clause would have no special status; it would be whatever clause happens to occur first. But there are two reasons why clause chaining in Northern Paiute does, in fact, have an asyndetic coordination structure.

\section{The linear order of the marked and unmarked clauses}

The alternative structure in 23 predicts that the simultaneous and sequential suffixes should occur nowhere else but between the marked and unmarked clauses. In fact, a marked clause — including the suffix - can occur after the unmarked clause. 
a. Yaisi $\mathrm{ka}=$ ggwitua tiggwisu ti=ddzotił'a ddiggwa'ni mani-kati, yaa paa'a-we PTC ACC=pail still REFL=hat look.like do-sit.IMPF there water-LOC kati-na. sit-SIM

'He still has the pail on his head that looks like a hat, while sitting in the water.' (prompted narrative, MS, BP24-1-t3, 42)

b. Yaisi yaa su=hibbi tihidda mia-hu, umi-ma sie-hu-si. PTC there NOM=thing deer go-PFV 2/3PL.ACC-LOC get.scared-PFV-SEQ

'The deer left because it got scared of them.' (prompted narrative, EM, BP25-2t1, 93-95)

This variability in the linear order of the marked and unmarked clauses is entirely expected if they are asyndetically coordinated. The sentences in $24 a-b$ would have the following schematic structure.

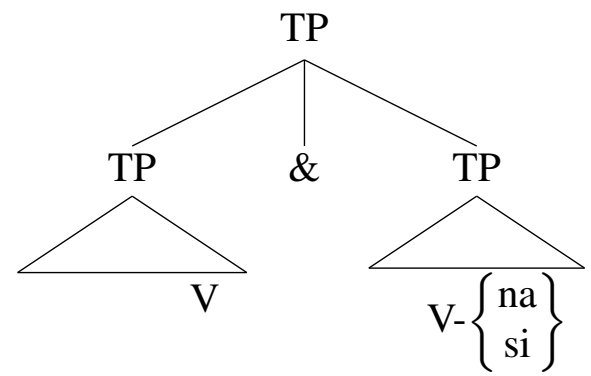

There might be a way of maintaining the alternative structure for clause chaining in 23 . As Haspelmath (2004:7f.) documents, in many languages, a coordinate can be extraposed to the end of the sentence, along with the coordinator. If the marked clause in $24 a-b$ were extraposed, though, then it should be an island for extraction, including across-the-board movement. In fact, whmovement in an across-the-board fashion is possible even when the marked clause follows the unmarked clause.

a. Himma ${ }_{1}$ su=naatsi'i $\mathbf{t}_{1}$ tika, yaisi su=mogo'ni=bino'o $\mathbf{t}_{1}$ tika-na? what NOM=boy eat.IMPF PTC NOM=woman=PTC eat-SIM

'What, while the woman eats it, does the boy eat, too?' (cf. What ${ }_{1}$ does the boy eat $t_{1}$, and the woman eat $t_{1}$, too?) (elicitation, EM, BP50-4, 29:14)

b. Haga ${ }_{1}$ su=nana $\mathbf{t}_{1}$ mutuhe-hu, su=naatsi'i=bino'o $\mathbf{t}_{1}$ mutuhe-hu-si?

who NOM=man kiss-PFV NOM=boy=PTC kiss-PFV-SEQ

'Who, after the boy kissed them, did the man kiss, too?' (cf. Who 1 did the man kiss $t_{1}$, and the boy kissed $t_{1}$, too?) (elicitation, EM, BP50-4, 31:34)

Since extraction is permitted from both clauses in $26 \mathrm{a}-\mathrm{b}$, these clause chains must have an asyndetic coordination structure.

\section{Interaction with aspectual morphology}

The simultaneous and sequential suffixes cannot themselves be coordinators because they interact with aspectual morphology inside the marked clause. In Northern Paiute, verbs cannot appear in a 
bare form in nonmodal contexts $(27 \mathrm{~A})$. They must minimally have morphology expressing either an imperfective aspect, such as the progressive (27b), or the perfective aspect (27k).

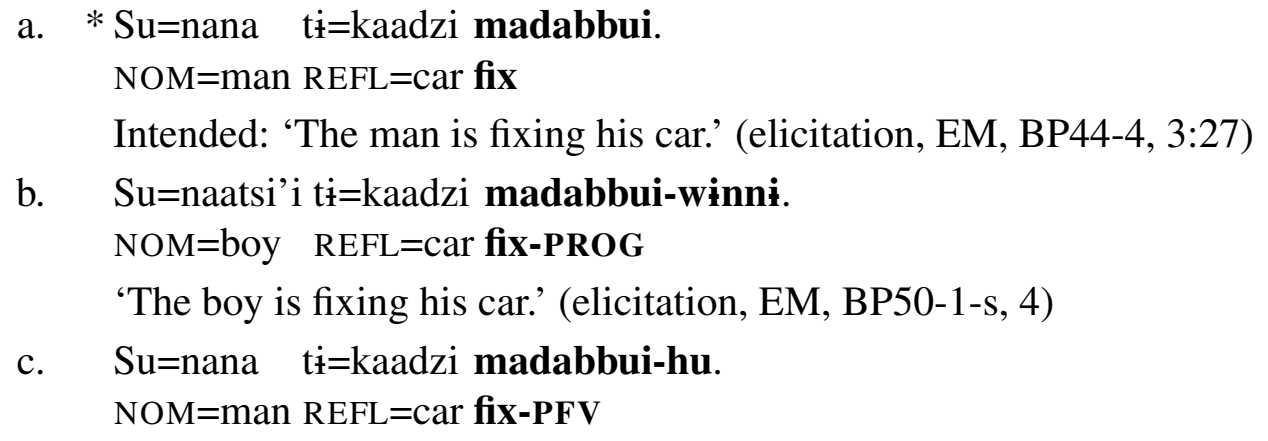

In the marked clause of a chain, however, the verb can appear without any aspectual morphology.
a. $\quad \mathrm{Su}=$ nana $\quad \mathrm{t} \mathbf{\mathrm { i }}=\mathrm{kaadzi}$ madabbui-na, hubiatu. NOM=man REFL=car fix-SIM sing.IMPF
'While the man is fixing his car, he is singing. (elicitation, EM, BP48-5, 38:03)
b. $\quad S u=n a n a ~ t i=k a a d z i$ madabbui-si, yaisi $u=d d z a-k a n a-g g i-h u$. $\mathrm{NOM}=$ man REFL=car fix-SEQ $\quad$ PTC 3SG.ACC=IP.fingers-grab-APPL-PFV

'After the man fixed his car, he started it.' (elicitation, EM and MS, BP50-1, 5:50)

If clause chaining had the alternative structure in 23 , where the simultaneous and sequential suffixes were themselves coordinators, then $28 \mathrm{a}-\mathrm{b}$ should be ungrammatical. The verb in the first coordinate would be in its bare form. While the suffixes' interaction with aspect remains to be explained, I conclude that they are contained inside the marked clause. Consequently, clause chaining in Northern Paiute must have an asyndetic coordination structure.

\section{The temporal contribution of the suffixes}

This coordination structure for clause chaining in Northern Paiute leaves us with something of a mystery. In general, coordinates must be alike in some syntactico-semantic sense (Huddleston and Pullum 2002:1323-1326). But the marked clause contains either the simultaneous or the sequential suffix, while the unmarked clause does not. As I will show next, though, this asymmetry turns out to result from a superficial difference between the marked and unmarked clauses. The suffixes are members of a syntactic category that is not phonologically overt in the unmarked clause.

What is this category? At first, it is tempting to treat the simultaneous and sequential suffixes as aspect, since as we saw in Section 1.3, they can appear on a bare verb in place of aspectual morphology. But they are not in complementary distribution with imperfective and perfective aspect $(29 a-b)$. Compare this with the progressive and perfective suffixes, which cannot cooccur (30a-b).

(29) a. Su=naatsi'i ti=kaadzi madabbui-winni-na, yaisi hubiadu-winni.

NOM=boy REFL=car make-PROG-SIM PTC sing-PROG

'While the boy is fixing his car, he is singing.' (elicitation, EM, BP50-1, 9:19) 
b. $\quad \mathrm{Su}=$ nana $\quad \mathrm{t} \mathbf{i}=$ kaadzi madabbui-hu-si, yaisi $\mathrm{u}=$ ddza-kana-ggi-hu.

NOM=man REFL=car fix-PFV-SEQ PTC 3SG.ACC=IP.fingers-grab-APPL-PFV

'After the man fixed his car, he started it.' (elicitation, EM, BP50-1-s, 1)

a. * Su=naatsi'i ti=kaadzi madabbui-winni-hu.

NOM=boy $\quad$ REFL=car make-PROG-PFV (elicitation, EM, BP50-1, 34:39)

b. * $\mathrm{Su}=$ naatsi'i ti=kaadzi madabbui-hu-winni.

NOM=boy $\quad$ REFL=car make-PFV-PROG （elicitation, EM, BP50-1, 34:46)

Instead, I take the simultaneous and sequential suffixes to be members of a syntactic category that selects for aspect. Specifically, I propose that they are members of T.

Among other things, this means that the simultaneous and sequential suffixes can select for overt aspectual morphology like the progressive and perfective suffixes - or, they can select for a phonological null member of Asp(ect) that is in complementary distribution with them.

The syntax of clause chaining in Northern Paiute (final version)

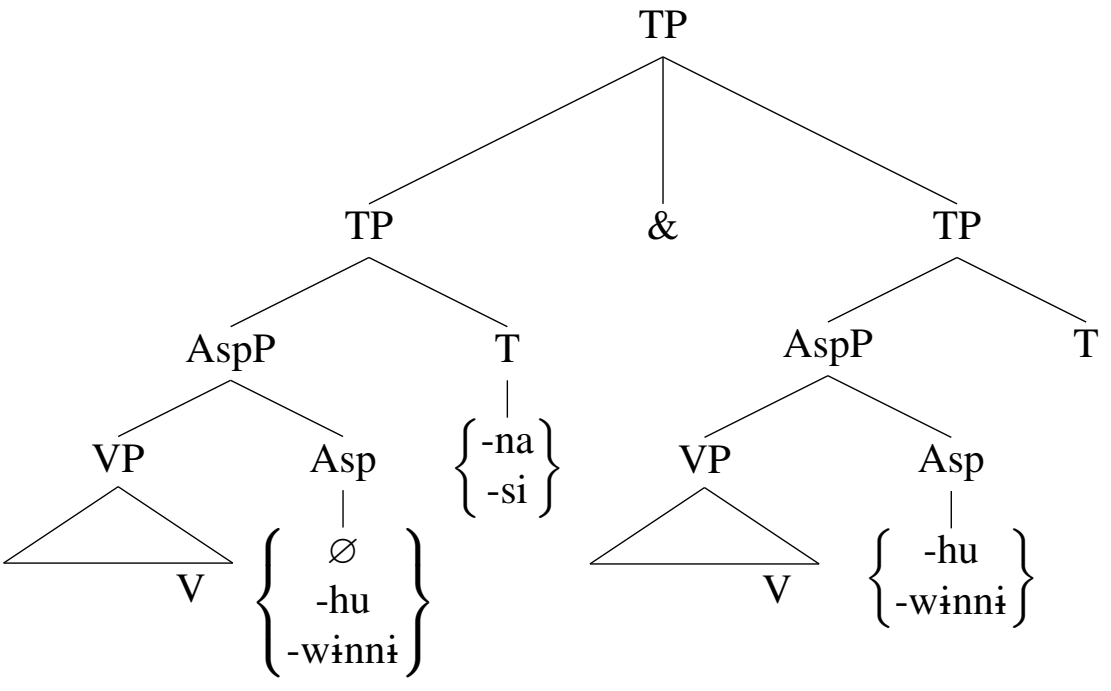

In the unmarked clause or in an independent sentence, $\mathrm{T}$ is not pronounced, and it must select for an overt member of Asp (perhaps for that reason). Thus, only in the marked clause of a chain can a verb appear without overt aspectual morphology.

Since Northern Paiute does not have absolute tense - on which more below - it is not surprising that $\mathrm{T}$ is phonologically null in the unmarked clause. But why, then, is the $\mathrm{T}$ head in marked clauses realized as the simultaneous and sequential suffixes? I propose that they convey relative tense, relating the time at which the marked clause is interpreted to an EVALUATION TIME, which can, but need not, be the time of utterance (Comrie 1985:56-64). Comrie assumes (p. 58) that the evaluation time is "provided by context," presumably through anaphora. But as we will see in the following section, this time interval must be identified with the time at which the unmarked clause is interpreted. Consequently, I will argue that the evaluation time of the the marked clause is abstracted over, much like tense in embedded clauses in Japanese (Ogihara 1994, 1995, 1996).

If a language does not have absolute tense, we might think that it should also lack relative tense. But historically, it might have had distinct morphemes for absolute and relative tense, and then just lost the set conveying absolute tense. Something like this probably happened in Northern Paiute. In Mono, the most closely related language, Lamb (1957;282) identifies an absolute tense marker 
-ti that "[i]ndicates present or near past time" - in other words, nonfuture tense. In Mono, we see directly that the simultaneous and sequential suffixes are members of $\mathrm{T}$, since as Lamb observes (p. 281), they are in complementary distribution with the nonfuture tense suffix.

Northern Paiute preserves the fossilized remnants of the nonfuture tense suffix. The so-called 'general tense' suffix - $t i$ optionally shows up in two morphological environments: (i) after the applicative suffix -ggi (Thornes 2003:398) and (ii) after some motion suffixes, including -dzaga, which indicates random motion, e.g. 19. While the general tense suffix is neither productive nor semantically contentful, it cannot cooccur with the simultaneous $(\sqrt[32]{a})$ and sequential $(32 \mathrm{p})$ suffixes.

a. $\quad$ Su=naatsi'i na-dika-ggi $(*$-ti)-na, yaka.
NOM=boy PASS-eat-APPL-TI-SIM cry.IMPF

'While the boy is being fed, he cries.' (elicitation, EM, BP40-5, 27:37)

b. Su=naatsi'i na-dika-ggi(*-ti)-si, yaisi iwi-huka.

NOM=boy PASS-eat-APPL-TI-SEQ PTC sleep-INCEP

'After the boy was fed, he fell asleep.' (elicitation, EM, BP40-5, 29:47)

The distribution of the remnants of absolute tense in Northern Paiute thus confirms that the simultaneous and sequential suffixes realize the $\mathrm{T}$ head in the marked clause.

For the moment, I will focus on the temporal contribution of the simultaneous and sequential suffixes. First, in Section 2.1. I provide some general background on tense and aspect in Northern Paiute. In particular, I give evidence that the language lacks absolute tense, while also sketching the semantics of the progressive and perfective suffixes. Then, in Section 2.2, I turn to the simultaneous suffix, which I argue conveys relative present tense. In contrast, as I contend in Section 2.3, the sequential suffix conveys relative past tense. Both suffixes can select either for an overt aspectual morpheme or for a null Asp head conveying (im)perfective aspect.

\subsection{Background on tense and aspect in Northern Paiute}

In one common framework for tense and aspect, a sentence is interpreted with respect to three times (Reichenbach 1947, Klein 1994). The EVENT TIME is the run time of the event described by the sentence. The REFERENCE TIME is the time which the sentence can broadly be said to be 'about,' relative to which the event time is positioned. The EVALUATION TIME is a time that restricts the location of the reference time.

Tense constrains the relation between the reference time and the evaluation time. For absolute tenses in a main clause, such as the present or past tense in English, the evaluation time is identified deictically - it is the time of utterance. The present tense establishes a relation of overlap between the reference time and utterance time. In contrast, the past tense locates the reference time before the utterance time. The future tense, if English had one, would locate the reference time after the utterance time.

Northern Paiute lacks absolute tense altogether, cf. Yukatec Maya (Bohnemeyer 2002), Kalaallisut (West Greenlandic; Shaer 2003, Bittner 2005), and Paraguayan Guaraní (Tonhauser 2011). While the sentence in 33 a) receives a default present interpretation, adding a temporal adverb results in a past (33) or future (33) ) interpretation. 
a. $\quad \mathrm{Su}=$ nana $\mathrm{t} i=k a a d z i$ madabbui-winni.

$\mathrm{NOM}=$ man $\mathrm{REFL}=$ car fix-PROG

'The man is fixing his car.' (elicitation, EM, BP46-3, 33:44)

b. Idzi'i ti=kaadzi madabbui-winni.

yesterday $\mathrm{REFL}=$ car fix-PROG

'He was fixing his car yesterday.' (elicitation, EM, BP44-4, 8:00)

c. Mu'a tínkaadzi madabbui-winni.

tomorrow REFL=car fix-PROG

'He will be fixing his car tomorrow.' (elicitation, EM, BP44-4-s, 8)

Crucially, in $33 \mathrm{a}-\mathrm{c}$, the form of the verb does not change; the reference time is constrained entirely by the temporal adverb. Since this takes place freely, Northern Paiute does not seem even to have a covert absolute tense that would restrict temporal interpretation to the nonfuture, as in St'áat'imcets (Matthewson 2006).

Aspect relates the reference time and the event time. In many languages without tense, aspect determines a default temporal interpretation. The progressive suffix, which conveys a type of imperfective aspect, gives rise to a default present interpretation (33a). In contrast, the perfective suffix gives rise to a default past interpretation $(34 a)$.
a. Su=nana $\mathrm{t} i=$ kaadzi madabbui-hu.
NOM=man REFL=car fix-PFV
'The man fixed his car.' (elicitation, EM and MS, BP44-4, 4:05)
b. Mino'o ti=kaadzi madabbui-hu.
now REFL=car fix-PFV
'He just fixed his car now.' (elicitation, EM, BP50-1-s, 10)
c. Mu'a ti=kaadzi madabbui-hu.
tomorrow REFL=car fix-PFV

'He will fix his car tomorrow.' (elicitation, EM, BP44-4-s, 6)

Again, this default past interpretation can be overridden by a temporal adverb, such as mino'o 'now' (34b) or mu'a 'tomorrow' (34k).

I am assuming that every clause is headed by $\mathrm{T}$, even though Northern Paiute does not have absolute tense. At the very least, this head has a formal function, assigning nominative case to, and agreeing with, the subject in Spec-TP. Semantically, in independent sentences and in the unmarked clause of a chain, it expresses the identity function. ${ }^{5}$

\footnotetext{
${ }^{5}$ I assume a type-theoretic, compositional semantics that has a rule of Function Application for interpreting complex constituents (cf. Heim and Kratzer 1998:49), as well as any other rules defined in the text. The truth conditions of a sentence, and the contribution that subparts of a sentence make to them, are represented by a predicate logic metalanguage with the lambda calculus. Constants are bolded. I use $x, y$, and $z$ as variables over individuals (type $e$ ); $e, e^{\prime}, e^{\prime \prime}$, etc. as variables over events (type $s$ ); $t, t^{\prime}, t^{\prime \prime}$, etc. as variables over time intervals (type $i$ ); and, $p, q$, and $r$ as variables over truth values (type $t$ ). In Section 4. I shift to a dynamic semantics in which the meaning of a sentence (still of type $t$ ) is a relation between context states. I use $i, j, k$, and $l$ as variables over context states. The only higher-order variables are $f, g$, and $h$, which range over functions from either individuals, events, or time intervals to truth valuesor, in the latter part of the paper, to relations between context states.
} 


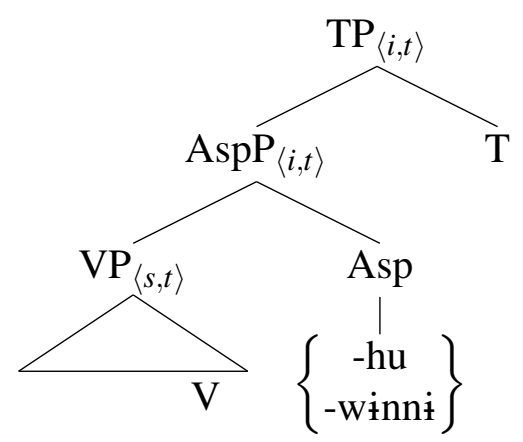

If aspect is a function from a property of events to a property of time intervals (Kratzer|1998), then $T$ returns this property of time intervals.

As a consequence, there must be an additional interpretive rule in Northern Paiute, so that a sentence has a truth value as its extension, not a set of time intervals (cf. Tonhauser 2011:288). I take this rule to saturate the reference time of root clauses with a free variable $\left(t_{r}\right)$.

\section{Root Clause Rule}

The final translation of a root clause translated as $\phi$ of type $\langle i, t\rangle$ is $\phi\left(t_{r}\right)$.

With the Root Clause Rule, sentences in Northern Paiute are anaphoric to a time interval, just as in a tensed language (Partee 1973, 1984). This temporal reference is not, of course, constrained relative to the utterance time by tense, though it can be restricted by other expressions, such as temporal adverbials.

\section{The progressive suffix}

Northern Paiute has a suffix that is traditionally called the continuous suffix (Thornes 2003:406). It conveys progressive aspect, since it depicts an event as ongoing.

a. Amamu'a su=naatsi'i ti=kaadzi madabbui-winni. Yaisi mino'o tiggwisu morning NOM=boy REFL=car make-PROG PTC now still madabbui-winni.

make-PROG

'This morning, the boy was fixing his car. He is still fixing it now.' (elicitation, MS, BP46-7, 3:10)

b. Idzi'i su=naatsi'i hubiadu-winni. Yaisi tiggwisu hubiadu-winni. yesterday NOM=boy sing-PROG PTC still sing-PROG 'Yesterday, the boy was singing. He is still singing.' (elicitation, EM, BP47-9, 33:00)

[EM: "He sang all night long."]

As a type of imperfective aspect, the progressive suffix does not entail termination of the event. It is thus compatible with an assertion of continuation (Smith 1997:63f.), for both accomplishment predicates $(37 \mathrm{a})$ and activity predicates $(37 \mathrm{~b})$. For the latter, the speaker's comments make clear that there is a single singing event that does not terminate within the reference time.

I assume the lexical entry in 38 for the progressive suffix in Northern Paiute. It existentially quantifies over the predicate's event argument, locating the reference time within a non-final subpart of its run time, as given by the temporal trace function $\tau(\operatorname{Link} \mid 1987$; 250). 
The semantics of the progressive suffix (static version)

$\llbracket$-winni $\rrbracket=\lambda f \lambda t \exists e\left(f(e) \wedge t \subset_{n f} \tau(e)\right):\langle\langle s, t\rangle,\langle i, t\rangle\rangle$

This meaning can be tested using temporal adverbial, which constrain the reference time - see Cover and Tonhauser (to appear) for discussion.

(39) a. Context: The boy started fixing his car at 1 o'clock; he finished fixing it at 3 o'clock.

Waha-ggwe su=naatsi'i ti=kaadzi madabbui-winni.

two-LOC NOM=boy REFL=car fix-PROG

'At two o'clock, the boy was fixing his car.' (elicitation, EM, BP50-2, 45:33)

b. Context: The boy started singing at 1 o'clock; he continued until 3 o'clock.

Waha-ggwe su=naatsi'i hubiadu-winni.

two-LOC NOM=boy sing-PROG

'At two o'clock, the boy was singing.' (elicitation, EM, BP50-2, 45:09)

In $39 \mathrm{a}-\mathrm{b}$, the reference time is restricted by the temporal adverbial wahaggwe 'at two o'clock' to the time interval at two o'clock. Both sentences are judged true in the contexts provided because they satisfy the lexical entry in 38 . The two o'clock time interval is included within a nonfinal segment of the fixing and singing events.

The progressive suffix also interacts in nontrivial ways with aktionsart. Since the reference time is properly included within the event time, the predicate must be durative, e.g. an activity (37 a) or an accomplishment (37b). The progressive suffix is not automatically compatible with other types of predicates.
a. \# Su=nana mia-winni. NOM=man go-PROG
Intended: 'The man is leaving.' (elicitation, EM, BP44-7, 1:24:13)
b. Nia huni-winni.
1SG.NOM fart-PROG
'I am farting (over and over again).' (elicitation, EM, BP44-6-s, 6)
[EM: "Means you're passing gas more, more than one."]

It is simply infelicitous with an achievement predicate like mia 'go' (40a). With semelfactive predicates, such as huni 'fart', it coerces an iterative interpretation (40p).

It will ultimately probably be necessary to provide a modal semantics for the progressive suffix (Dowty 1977, 1979: 133-192, Landman 1992, Portner 1998). Like the progressive in English, it exhibits the imperfective paradox (Dowty|1979:133).
a. Su=mogo'ni ka=poo wokwopa-winni. Su=kaadzi
NOM=woman ACC=road cross-PROG $\quad \mathrm{NOM}=\mathrm{car}$
u=wi-dzaga-hu-kaa.
3SG.ACC=IP.long.thing-strike-PFV-MOT

'The woman was crossing the road. The car hit her and ran.' (elicitation, EM, BP50-1, 1:17:26)

[MT: "Does she make it all the way to the other side of the street, or no?" EM: "Probably not, if they hit her in the road."] 
With the progressive suffix, the accomplishment predicate $k a=$ poo wokwopa 'cross the street' describes an event that does not have to culminate in the actual world.

\section{The perfective suffix}

In Northern Paiute, perfective aspect is conveyed by what is traditionally called the punctual suffix (Thornes 2003:406ff.). It portrays an event in its totality; for accomplishment predicates, which are inherently telic, it entails their culmination 42 a).
a. \# Amamu'a su=naatsi'i ti=kaadzi madabbui-hu. Yaisi mino'o tiggwisu morning NOM=boy REFL=car make-PFV PTC now still madabbui-winni.
make-PROG

Intended: 'This morning, the boy fixed his car. He is still fixing it now.' (elicitation, MS, BP46-7, 2:09)

[MS: "No, he don't cuz he's already finished it, and then..." EM: "Yeah, he already done it in the morning, so... he finished it in the morning."]

b. \# Idzi'i su=naatsi'i hubiadu-hu. Yaisi tiggwisu hubiadu-winni.

yesterday NOM=boy sing-PFV PTC still sing-PROG

Intended: 'Yesterday, the boy sang. He is still singing.' (elicitation, EM, BP47-6, 4:06)

[EM: "He sang yesterday, then he started to sing again, today."]

Somewhat surprisingly, with activity predicates, the perfective suffix is also incompatible with an assertion of continuation, even though they are not telic. Speakers comment that $42 \mathrm{p}$ is true only if there is more than one discontinuous singing event 6

For this reason, I take the perfective suffix in Northern Paiute to introduce maximization over events, cf. perfective aspect in Dëne Sưłiné (Wilhelm 2007:47-53). The event must be the largest that satisfies the predicate's event description. This ensures even for an atelic predicate like hubiadu 'sing' that it terminates within the reference time.

\footnotetext{
${ }^{6}$ It can be shown independently that there is a distinction between activity and accomplishment predicates in Northern Paiute. As in English (Dowty 1979.58), the adverb $t u$ ' $i$ 'almost' entails that the event has not begun when it modifies an activity predicate. But with accomplishments, it can entail that the event began but did not culminate.
}

(i) Context: The boy is singing now.

\# Su=naatsi'i tu'i hubiadu-hu.

NOM=boy almost sing-PFV

'The boy almost sang.' (elicitation, EM, BP51-6, 13:00)

[EM: "Isaya'e ['Lying'], I guess.”]

(ii) Context: The man is fixing his car now.

$\mathrm{Su}=$ nana ti=kaadzi'i tu'i madabbui-hu.

NOM=man REFL=car almost make-PFV

'The man almost fixed his car.' (elicitation, EM, BP51-6, 14:25)

[EM: "It's probably true, init? Cuz he's still working on it, he's not through. Yeah, that would be true."]

The sentence in (i) is judged false in a context where the boy has started singing. In contrast, the sentence in (iii) is judged as true in the parallel context where the man has started fixing his car but has not yet finished it. 
The semantics of the perfective suffix (static version)

$$
\llbracket-\mathrm{hu} \rrbracket=\lambda f \lambda t \exists e\left(f(e) \wedge \neg \exists e^{\prime}\left(e \subset e^{\prime} \wedge f\left(e^{\prime}\right)\right) \wedge \tau(e) \subseteq t\right):\langle\langle s, t\rangle,\langle i, t\rangle\rangle
$$

Otherwise, this is a standard semantics for perfective aspect; the event time is included in the reference time (Kratzer 1998; 107).

Again, the lexical entry in 43 can be tested using temporal adverbials. A sentence containing the perfective suffix is true in a context where the event time is located within the reference time, restricted by $i d z i$ ' $i$ 'yesterday'.

(44) a. Context: The boy fixed his car yesterday from 9 o'clock until 12 o'clock.

Idzi'i su=naatsi'i ti=kaadzi madabbui-hu.

yesterday NOM=boy REFL=car fix-PFV

'Yesterday, the boy fixed his car.' (elicitation, EM, BP50-4, 1:04:45)

b. Context: The boy sang yesterday from 9 o'clock until 12 o'clock.

Idzi'i su=naatsi'i hubiadu-hu.

yesterday NOM=boy sing-PFV

'Yesterday, the boy sang.' (elicitation, EM, BP50-4, 1:00:59)

Crucially, the perfective suffix must also be incompatible with an imperfective viewpoint (Cover and Tonhauser, to appear). This is indeed the case.

(45) a. Context: The boy started fixing his car at 1 o'clock; he finished fixing it at 3 o'clock.

\# Waha-ggwe su=nana ti=kaadzi madabbui-hu.

two-LOC NOM=man REFL=car fix-PFV

Intended: 'At two o'clock, the man was fixing his car.' (elicitation, EM, BP51-6, 38:00)

[EM: “Isaya'e ['Lie'].”]

b. Context: The boy started singing at 1 o'clock; he continued until 3 o'clock.

\# Waha-ggwe su=naatsi'i hubiadu-hu.

two-LOC NOM=boy sing-PFV

Intended: 'At two o'clock, the boy was singing.' (elicitation, EM, BP51-6, 37:10) [EM: "Probably isaya'e ['lie']."]

The sentences in $45 \mathrm{a}-\mathrm{b}$ are judged false because the reference time is restricted by the punctual time adverbial wahaggwe 'at two o'clock' to such a small time interval that it cannot include the event time.

\subsection{The simultaneous suffix}

Moving on now to the simultaneous suffix, I propose that it is a relative present tense. It existentially quantifies over the reference time in the marked clause, locating it within the evaluation time.

The semantics of the simultaneous suffix (static version)

$\llbracket$-na $=\lambda f \exists t\left(f(t) \wedge t_{1} \subseteq t\right):\langle\langle i, t\rangle, t\rangle$ 


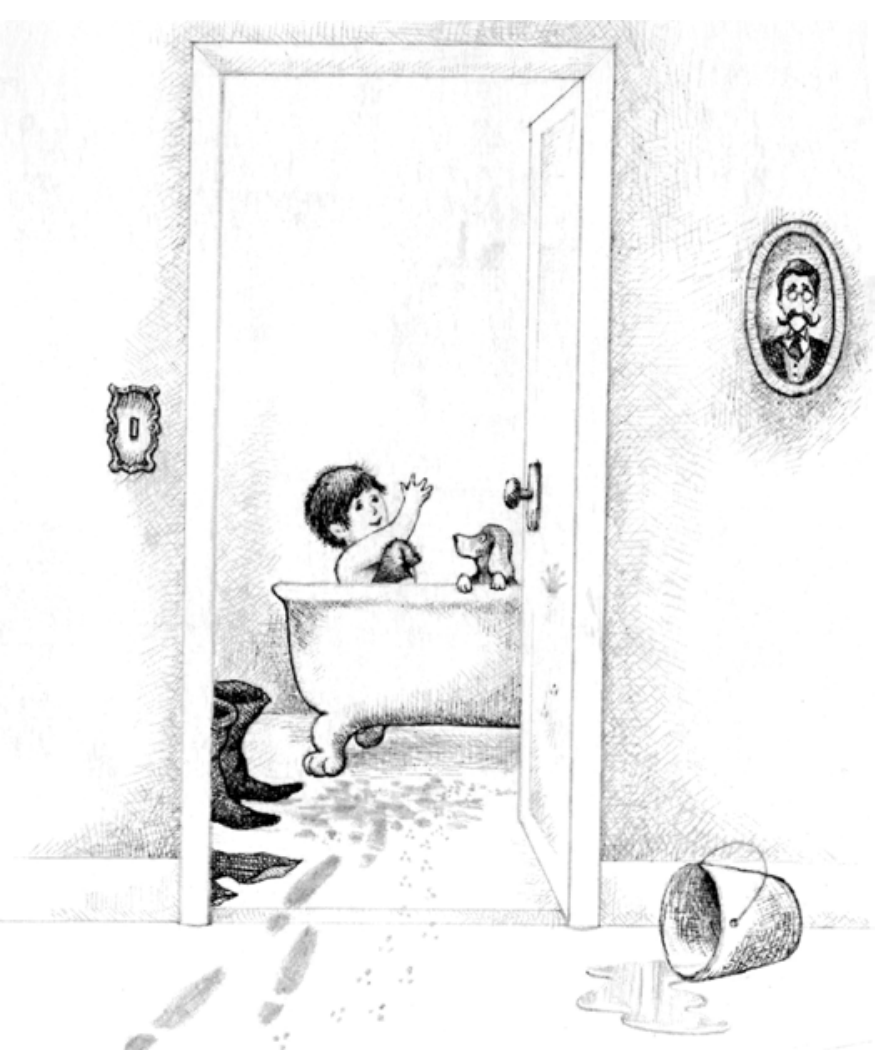

Figure 1: The boy is bathing. The dog is sitting and looking at him in the bathtub. (Mercer Mayer. 1969. Frog, where are you? New York: Dial Books.)

The evaluation time itself is a free variable $\left(t_{1}\right)$ that will ultimately be abstracted over and identified with the reference time of the unmarked clause. This establishes at least a relation of temporal overlap between the marked and unmarked clauses.

This lexical entry thus correctly accounts for the meaning of the clause chain in $47 \mathrm{a}$. It is judged true in the context in Figure 1, where the bathing and looking events occur at the same time.
a. Su=tïtsi-'yu naatsi'i nabagia-winni-na, su=ddoogga nabagia-na-ggwe NOM=little-NOM boy bathe-PROG-SIM NOM=dog bathe-NMLZ-LOC $\mathrm{u}=$ bbuni-kati.
3SG.ACC $=$ see-sit.IMPF

'While the little boy is bathing, the dog is sitting and looking at him in the bathtub.' (elicitation, EM, BP53-3, 57:25)

b. \# Su=tiitsi-'yu naatsi'i nabagia-hu-si, su=ddoogga nabagia-na-ggwe NOM=little-NOM boy bathe-PFV-SEQ NOM=dog bathe-NMLZ-LOC $\mathrm{u}=$ bbuni-kati.

3SG.ACC $=$ see-sit.IMPF

'After the little boy bathed, the dog is sitting and looking at him in the bathtub.' (elicitation, EM and MS, BP53-3, 1:00:15)

[MS: "Nabagiahusi means he's through bathing." EM: "Probably isaya'e init?"] 
In contrast, when the marked clause contains the sequential suffix, the clause chain is judged as false in the same context 47b).

As we have already seen, the simultaneous suffix can appear without any overt aspectual marking (48 $)$ ) or with the progressive suffix -winni $(48 \mathrm{~b})$. At least in an out-of-the-blue context, it is not compatible with the perfective suffix 48 r).

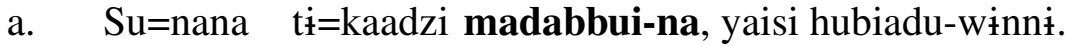 NOM=man REFL=car fix-SIM PTC sing-PROG
'While the man is fixing his car, he is singing.' (elicitation, EM, BP52-2, 12:31)
b. $\quad S u=$ naatsi'i ti=kaadzi madabbui-winni-na, yaisi hubiadu-winni. NOM=boy REFL=car make-PROG-SIM PTC sing-PROG
'While the boy is fixing his car, he is singing.' (elicitation, EM, BP50-1, 9:19)
c. * Su=nana ti=kaadzi madabbui-hu-na, yaisi hubiadu-winni. NOM=man REFL=car make-PFV-SIM PTC sing-PROG
Intended: 'After the man finished fixing his car, he is singing.' (elicitation, EM, BP50-1, 10:15)

I take this to mean that the simultaneous suffix selects for imperfective aspect. Crosslinguistically, it is common for the present tense to be incompatible with an event described from a perfective viewpoint. This restriction is sometimes said to arise because an event that overlaps with the time of utterance "by definition [... ]could not be viewed as bounded" (Bybee et al. 1994:83). If this explanation is correct, then it needs to be generalized to account for the simultaneous suffix, which is by hypothesis a relative present tense.

What is the aspect of the marked clause when there is no overt aspectual morpheme? Since the simultaneous suffix takes a predicate of time intervals as its argument, it must coerce some relation between the event time and the reference time. This relation is characteristic of an imperfective aspect, such as the progressive.

Context: The man started fixing his car and singing at 1 o'clock; he finished at 3 o'clock.

Waha-ggwe su=nana $\quad \mathrm{t} i=k a a d z i$ madabbui-na, hubiadu-winni.

two-LOC NOM=man REFL=car fix-SIM sing-PROG

'At two o'clock, while the man was fixing his car, he was singing.' (elicitation, EM, BP52-2, 15:40)

Even without the progressive suffix, the reference time of the marked clause can be restricted by wahaggwe 'at two o' clock' in 49, so that it is included within a nonfinal segment of the event time.

For concreteness, I assume that when there is no overt aspectual morpheme, the simultaneous suffix selects for an Asp head that is phonologically null. It has the same semantics as the progressive suffix.

$$
\llbracket \varnothing_{\mathrm{PROG}} \rrbracket=\lambda f \lambda t \exists e\left(f(e) \wedge t \subset_{n f} \tau(e)\right):\langle\langle s, t\rangle,\langle i, t\rangle\rangle
$$

This lexical entry correctly predicts that the marked clause is compatible with an assertion of continuation for both accomplishment $(51 \mathrm{a})$ and activity $(51 \mathrm{~b})$ predicates, even when it does not contain overt morphology expressing imperfective aspect. 
a. $\quad \mathrm{Su}=$ nana $\mathrm{t} i \mathrm{i}=$ kaadzi madabbui-na, yaisi tiggwisu $\mathrm{u}=$ madabbui-winni. $\mathrm{NOM}=$ man REFL=car fix-SIM PTC still 3SG.ACC=fix-PROG

'The man was fixing his car, and he is still fixing it.' (elicitation, EM, BP51-7, 42:10)

b. $\quad \mathrm{Su}=$ nana hubiadu-na, yaisi tiggwisu hubiadu-winni.

NOM=man sing-SIM PTC still sing-PROG

'The man was singing, and he is still singing.' (elicitation, EM, BP51-7, 41:23)

Similarly, the simultaneous suffix should interact in nontrivial ways with aktionsart. Just as with the progressive aspect, the simultaneous suffix all by itself is incompatible with achievements (52a) and induces an iterative interpretation with semelfactives $(52 \mathrm{~b})$.

a. \# Su=nana mia-na, hubiatu.

Intended: 'While the man is leaving, he is singing.' (elicitation, EM, BP48-5, 21:08)

b. Su=naatsi'i huni-na, nabagi'a.

NOM=boy fart-SIM bathe.IMPF

'While the boy is farting, he is taking a bath.' (elicitation, EM and MS, BP49-5, $1: 36: 37)$

[MT: "Could it have been more than once?" MS: "Yeah, it can be more than one." EM: "Yeah." MS: "Probably make couple bubbles."]

There are contexts in other languages where aspect is not overtly marked. The future tense in French, for instance, is ambiguous between imperfective and perfective viewpoints. Because it can have either of these aspectual interpretations, Smith (1997:77-81) proposes that the future tense in French expresses a default aspect - the so-called neutral aspect - that has a relatively underspecified meaning. The neutral aspect requires the reference time to include only the initiation of an event, though it can optionally also include its termination (see also Pancheva 2003:282). But in Northern Paiute, when there is no overt aspectual morphology, the simultaneous suffix is not interpreted with the neutral aspect that Smith proposes. In $49 \mathrm{a}-\mathrm{b}$, the reference time is included entirely in the process component of an accomplishment or activity, where it does not include the initiation of the event 7

\subsection{The sequential suffix}

I propose that the sequential suffix conveys a relative past tense: it existentially quantifies over the reference time in the marked clause and locates it before the evaluation time.

\section{The semantics of the sequential suffix (static version)} $\llbracket$-si $=\lambda f \exists t\left(f(t) \wedge t<t_{1}\right):\langle\langle i, t\rangle, t\rangle$

Again, the evaluation time is a free variable $\left(t_{1}\right)$ that will be abstracted over and identified with the reference time of the unmarked clause. This establishes a relation of temporal precedence between the marked clause and unmarked clause.

\footnotetext{
$\sqrt[7]{\text { Schaden }}$ (2011:108-110) makes a similar argument even for the future tense in French.
} 

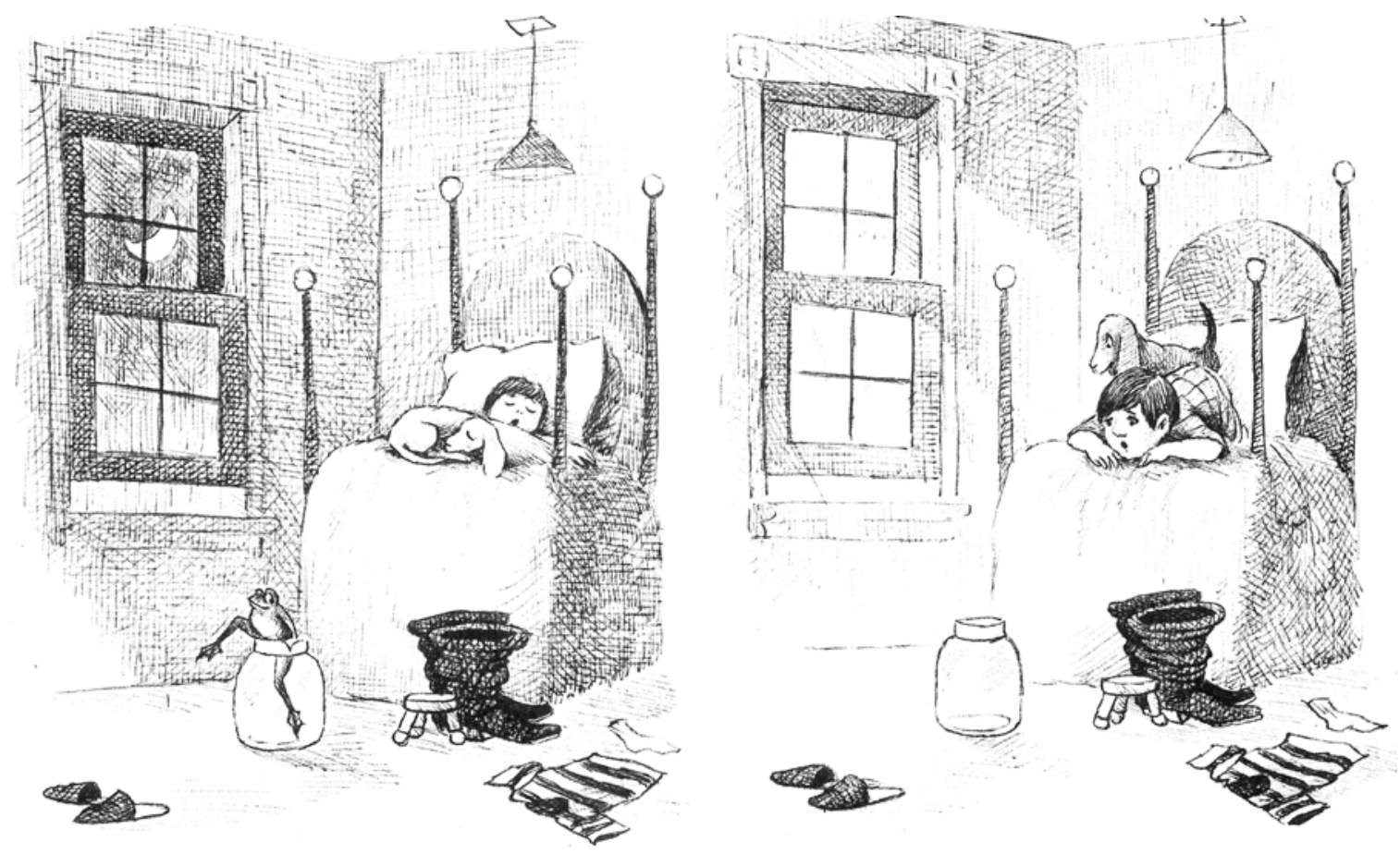

Figure 2: While the boy is asleep, the frog escapes. After the boy wakes up, he notices the frog is gone. (Mercer Mayer. 1969. Frog, where are you? New York: Dial Books.)

Just as predicted, then, the clause chain in $54 \mathrm{a}$ is judged true in the context depicted in Figure 2. where the event of the boy waking up precedes the event of him discovering that the frog is missing.

a. $\quad S u=$ naatsi'i tibuni-hu-si, $\quad$ ti $=$ pa' mogo yaa-hu.

NOM=boy wake.up-PFV-SEQ REFL=frog miss-PFV

'After the boy woke up, he missed his frog.' (elicitation, EM, BP53-3, 1:06:05)

b. \# Su=naatsi'i tibuni-winni-na, ti=pa'mogo yaa-hu.

NOM=boy wake.up-PROG-SIM REFL=frog miss-PFV

Intended: 'While the boy was waking up, he missed his frog.' (elicitation, EM and MS, BP53-3, 1:07:08)

[EM: "Probably would be lying, init?[...]" MS: "He not quite awake." EM: "He's not real awake."]

The parallel clause chain with the simultaneous suffix in 54p is judged false in the same context, by contrast, since it requires the marked clause to temporally include the unmarked clause.

Unlike the present tense, the past tense is not, in general, incompatible with perfective aspect. The sequential suffix cooccurs with both the progressive suffix -winni $(55 \mathrm{~b})$ and with the perfective suffix (55c). 
a. $\quad \mathrm{Su}=$ nana $\quad$ ti $=$ kaadzi madabbui-si, yaisi $u=d d z a-k a n a-g g i-h u$.

NOM=man REFL=car fix-SEQ

PTC 3SG.ACC=IP.fingers-grab-APPL-PFV

'The man fixed his car, and then he started it.' (elicitation, EM and MS, BP50-1, 5:50)

b. $\quad \mathrm{Ti}=$ kaadzi madabbui-winni-si, yaisi sonapina-pinni.

REFL=car fix-PROG-SEQ PTC take.break-STAT

'He was fixing his car, and then he took a rest.' (elicitation, EM, BP50-1-s, 6)

c. $\quad \mathrm{Su}=$ nana $\quad \mathrm{t} \dot{\mathrm{i}}=$ kaadzi madabbui-hu-si, yaisi u=ddza-kana-ggi-hu.

NOM=man REFL=car fix-PFV-SEQ PTC 3SG.ACC=IP.fingers-grab-APPL-PFV

'The man fixed his car, and then he started it.' (elicitation, EM, BP50-1-s, 1)

When the sequential suffix appears without overt aspectual morphology, e.g. 55 a, I propose that it, too, must select for a phonologically null Asp head.

As a default, this has the same semantics as the perfective suffix.

$$
\llbracket \varnothing_{\mathrm{PFV}} \rrbracket=\lambda f \lambda t \exists e\left(f(e) \wedge \neg \exists e^{\prime}\left(e \subset e^{\prime} \wedge f\left(e^{\prime}\right)\right) \wedge \tau(e) \subseteq t\right):\langle\langle s, t\rangle,\langle i, t\rangle\rangle
$$

Accordingly, it should be possible for the reference time of the marked clause to include the event time, even if the sequential suffix does not select for the perfective suffix. This is indeed the case.

Context: The boy started and finished singing yesterday. Now, he's dancing.

a. Idzi'i su=naatsi'i hubiadu-si, mino'o niga-winni. yesterday NOM=boy sing-SEQ now dance-PROG

'Yesterday, the boy sang, and now he is dancing.' (elicitation, EM, BP52-2, 28:20)

b. Idzi'i su=naatsi'i hubiadu-hu-si, mino'o niga-winni. yesterday NOM=boy sing-PFV-SEQ now dance-PROG

'Yesterday, the boy sang, and now he is dancing.' (elicitation, EM, BP52-2, 29:20)

The singing event described by the marked clause in $57 \mathrm{~h}$ is included within the reference time delimited by idzi'i 'yesterday'. The control sentence with the perfective suffix in 57p is judged true in the same context.

If the sequential suffix can only select for the phonologically null Asp head in 56, then it should always entail event termination. Somewhat surprisingly, however, even when there is no overt marker of imperfective aspect, the sequential suffix is compatible with an assertion of continuation.

a. $\quad$ Su=naatsi'i tí=kaadzi madabbui-si, yaisi tiggwisu u=madabbu'i.

NOM=boy REFL=car make-SEQ PTC still 3SG.ACC=make.IMPF

'After the boy was fixing his car, he was still fixing it.' (elicitation, EM and MS, BP49-3, 1:19:55)

b. $\quad S u=n a a t s i ' i$ ti=kaadzi madabbui-winni-si, yaisi tiggwisu u=madabbu'i.

NOM=boy REFL=car make-PROG-SEQ PTC still 3SG.ACC=make.IMPF

'After the boy was fixing his car, he was still fixing it.' (elicitation, EM, BP52-2, 39:15) 
c. \# Su=naatsi'i tí=kaadzi madabbui-hu-si, yaisi tiggwisu u=madabbu'i.

NOM=boy REFL=car make-PFV-SEQ PTC still 3SG.ACC=make.IMPF

Intended: 'After the boy was fixing his car, he was still fixing it.' (elicitation, EM and MS, BP49-3, 1:16:19)

[EM: “No, you can't say that." MS: "No, madabbuihusi means he's done, he's gone."]

It is not contradictory to follow up the marked clause in 58 a with an assertion that the event is still ongoing. Such an assertion of continuation is also possible when the marked clause contains the progressive suffix (58) $)$, but not the perfective suffix (58).

To account for this fact, I propose that the sequential suffix can select for a phonologically null Asp head that conveys either perfective aspect (56) or imperfective aspect (50). It selects for the latter in $58 \mathrm{a}$, so that no contradiction arises. This predicts that the reference time of the marked clause should be able to be included within the event time.

(59) Context: The man started fixing his car at 1 o'clock; he finished fixing it at 3 o'clock. At 2 o'clock, while he was fixing his car, the woman came into the house.

a. Waha-ggwe su=nana ti=kaadzi madabbui-si, su=mogo'ni nobi-ggwe two-LOC NOM=man REFL=car fix-SEQ NOM=woman house-LOC iga-hu. enter-PFV

'At two o'clock, the man was fixing his car, and then the woman came into the house.' (elicitation, EM, BP52-2, 45:47)

b. \# Waha-ggwe su=nana ti=kaadzi madabbui-hu-si, su=mogo'ni nobi-ggwe two-LOC NOM=man REFL=car fix-PFV-SEQ NOM=woman house-LOC iga-hu. enter-PFV

Intended: 'At two o'clock, the man was fixing his car, and then the woman came into the house.' (elicitation, EM and MS, BP52-3, 35:00)

[EM: "Probably isaya'e ['lie'], init?[...]Then he worked till three."]

c. Waha-ggwe su=nana $\quad \mathrm{t} i=k$ aadzi madabbui-winni-si, su=mogo'ni two-LOC NOM=man REFL=car fix-PROG-SEQ NOM=woman nobi-ggwe iga-hu. house-LOC enter-PFV

'At two o'clock, the man was fixing his car, and then the woman came into the house.' (elicitation, EM, BP52-2, 46:45)

Indeed, when the sequential suffix does not select for overt aspectual morphology, the reference time can be included within the process component of an event $(59 \mathrm{a})$. Crucially, this is also the case when it selects for the progressive suffix (59k), but not the perfective suffix (59b).

I have been treating the sequential suffix as a type of tense-rather than aspect-because the marked clause can have both imperfective and perfective interpretations. The combination of past tense and perfective aspect is not, however, that different from perfect aspect, which locates the reference time after the event time, at least under one analysis (Klein 1994:109). It is possible, Bohnemeyer (to appear) observes, to distinguish these alternatives using temporal adverbials. 
(60) Context: The man started fixing his car at 9 o'clock; he finished fixing it at 12 o'clock. He drove off at 2 o'clock.

a. \# Waha-ggwe su=nana $t \dot{t}=k a a d z i$ madabbui-si,

two-LOC NOM=man REFL=car fix-SEQ

$\mathrm{u}=$ ddza-mia-ggi-huka.

3SG.ACC=IP.fingers-go-APPL-INCEP

Intended: 'At two o' clock, the man finished fixing his car, and then he drove it off.' (elicitation, EM, BP50-7, 15:40)

[EM: "Well, you're lying[... ]because you finished it at twelve o'clock."]

b. \# Waha-ggwe su=nana ti=kaadzi madabbui-hu-si,

two-LOC NOM=man REFL=car fix-PFV-SEQ

u=ddza-mia-ggi-huka.

3SG.ACC $=$ IP.fingers-go-APPL-INCEP

Intended: 'At two o'clock, the man finished fixing his car, and then he drove it off.' (elicitation, EM, BP50-7, 14:42)

[EM: "Isaya'e['Lie'... ]because he finished his car at twelve o'clock.']

When the marked clause contains no overt aspectual morphology, the reference time cannot follow the event time $(60 \mathrm{a})$. This is also true when it selects for the perfective suffix $(60 \mathrm{p})$. In neither example does the marked clause receive a perfect interpretation. Consequently, the sequential suffix itself must convey relative past tense.

\section{The temporal semantics of clause chaining}

How do these semantics for the simultaneous and sequential suffixes give rise to the temporal interpretation of clause chaining? In unmarked clauses, $T$ does not saturate the reference time, so that this entire TP is a property of time intervals (type $\langle i, t\rangle$ ).

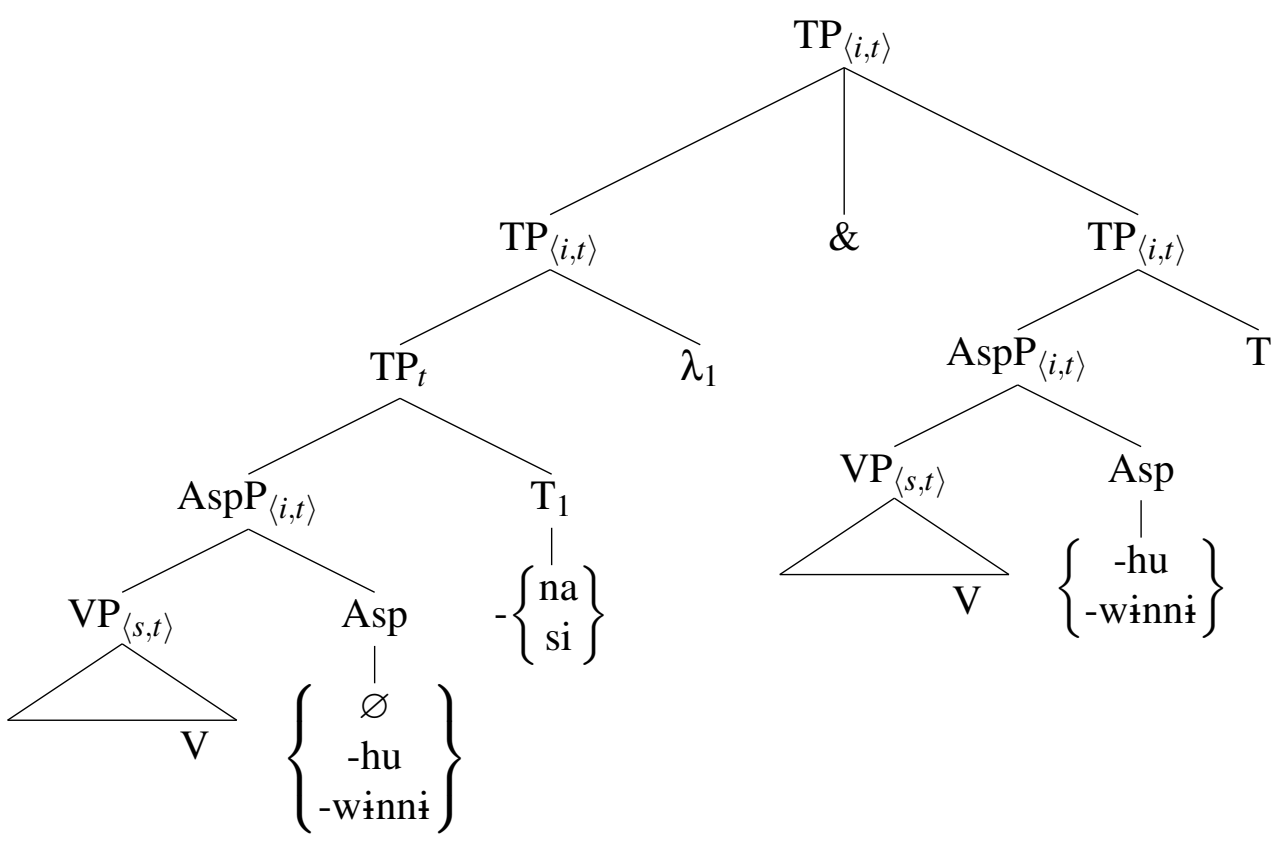


Within a static semantics, the asyndetic coordinator in Northern Paiute expresses a generalized version of logical conjunction (Rooth and Partee 1982); its lexical entry contains at least the following function. 8

$$
\begin{aligned}
& \text { The semantics of asyndetic coordination (static version) } \\
& \llbracket \& \rrbracket=\lambda f \lambda g \lambda t(f(t) \wedge g(t)):\langle\langle i, t\rangle,\langle\langle i, t\rangle,\langle i, t\rangle\rangle\rangle
\end{aligned}
$$

For the marked clause to combine with the unmarked clause in this coordination, it must also express a property of time intervals. While $\mathrm{T}$ in the marked clause - the simultaneous or sequential suffix - does not automatically provide this meaning, it does introduce a free variable as the evaluation time. I propose that this is abstracted over, so that the marked clause expresses a property of times that can be conjoined with the unmarked clause. The evaluation time of the marked clause thus ends up being identified with the reference time of the unmarked clause.

In this respect, the marked clause in a coordination structure in Northern Paiute behaves like an embedded clause in other languages. For instance, in Japanese, the complements of attitude verbs, relative clauses, and temporal adjunct clauses all allow for abstraction over the evaluation time of a (relative) present or past tense, relating it to the time of the matrix clause (Ogihara 1994, 1995, 1996).9 In Northern Paiute, a language that lacks absolute tense, each clause in a coordination structure must express a property of time intervals, including the marked clause. This meaning can only arise by abstracting over the free time variable introduced by the simultaneous and sequential suffixes.

Presumably, it is because the simultaneous and sequential suffixes convey relative tenses that they cannot occur in an independent sentence. This syntactic context does not allow for abstraction over the free time variable. We might, however, expect the simultaneous and sequential suffixes to appear in other contexts that do provide for abstraction, such as embedded clauses. Unfortunately, Northern Paiute has only one other subordination strategy besides deverbal nominalization (Toosarvandani, to appear). Direct and indirect quotes are introduced by the quotative particle mii, which either precedes or follows the embedded clause; there may or may not be an overt verb of saying. The suffixes seem to be able to occur in these quotative clauses.

\footnotetext{
${ }^{8}$ I have been assuming a simple ternary branching structure for coordination. Given this syntax, the coordinator with the lexical entry in 62 will not technically be able to combine with its arguments by Function Application (cf. Heim and Kratzer 1998:49). Instead, I assume the following composition rule for coordination structures.
}

$$
\llbracket \mathrm{XP}_{1} \& \mathrm{XP}_{2} \rrbracket=\llbracket \& \rrbracket\left(\llbracket \mathrm{XP}_{1} \rrbracket\right)\left(\llbracket \mathrm{XP}_{2} \rrbracket\right)
$$

This rule is sensitive to the linear order of the coordinates - $\mathrm{XP}_{1}$ precedes $\mathrm{XP}_{2}$. This is not particularly relevant for the static semantics in 62. But it will become crucial later on in Section 4 , when I introduce a dynamic meaning for asyndetic coordination.

${ }^{9}$ In other languages, this binding of tense may be restricted to intensional contexts, e.g. English (Abusch 1997), Hebrew (Hatav 2010), and Russian (Barentsen 1996, Schlenker 2003:70f.). See Ogihara and Sharvit 2012 for a recent discussion of this crosslinguistic variation. 
'Out there while hunting, they would find some groundhog, probably under the rocks, somewhere out there, and by barking, they would continually make noise. They probably saw them underneath there, those groundhogs.'

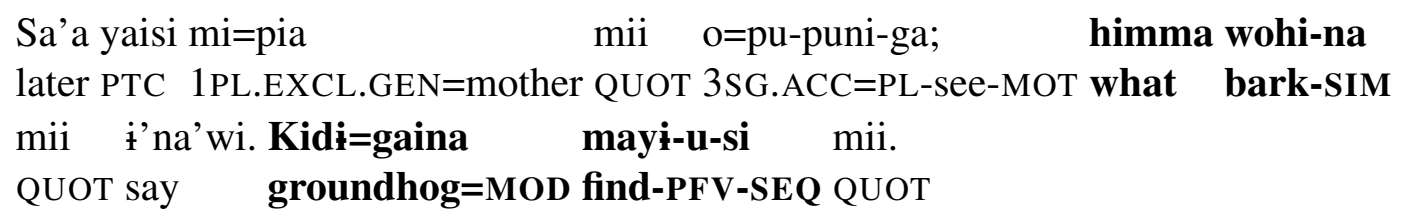

'Later then, our mother said, "Go check on them!" "What they are barking at," said. "Must have found a groundhog,” said.' (narrative, Nepa Kennedy, "Root-Digging Time”, Thornes, p.c.)

With a simultaneous suffix inside the quotative clause, the speaker conveys that the dogs are barking at the same time that she is speaking. With a sequential suffix, she conveys that the dogs finding the groundhogs took place at a time that precedes her speaking time.

To show how my account gives rise to the entailments for clause chaining, I go through a detailed derivation for some basic cases in Section 3.1. This meaning should not be affected by the linear order of the clauses in a chain, if they are related by semantic binding. Indeed, in Section 3.2. I show that a marked clause containing the sequential suffix always temporally precedes the unmarked clause, regardless of whether it precedes or follows it linearly. This account also provides relatively weak truth conditions for clause chains that contain multiple marked clauses. This is necessary, I argue in Section 3.3. for when the marked clauses are not temporally related to one another.

\subsection{Deriving temporal simultaneity and sequence}

Consider the following clause chain containing the simultaneous suffix, repeated from $48 \mathrm{p}$ above.

$$
\mathrm{Su}=\text { naatsi' } i \mathrm{ti}=\text { kaadzi madabbui-winni-na, yaisi hubiadu-winni. }
$$

NOM=boy $\quad$ REFL=car make-PROG-SIM PTC sing-PROG

'While the boy is fixing his car, he is singing.' (elicitation, EM, BP50-1, 9:19)

As shown in Figure 3, the unmarked clause expresses a property of time intervals (1). Before $\lambda$ abstraction, the marked clause denotes a truth value (2). Once the free time variable introduced by the simultaneous suffix is abstracted over, the marked clause also expresses a property of time intervals (3). The asyndetic coordinator combines the marked and unmarked clauses to yield a conjoined property of time intervals (4). Consequently, once the Root Clause Rule has applied, the whole clause chain is true at some time provided by context just in case: (i) that time is included in a time that is itself included in a nonfinal segment of an event of the boy fixing his car, and (ii) it is included in a nonfinal segment of an event of the boy singing (5). In other words, it is true just in case the two events overlap in time.

The semantic derivation for the following clause chain containing the sequential suffix, repeated from 54 , proceeds in the same way.

$$
\begin{aligned}
& \mathrm{Su}=\text { nana ti=kaadzi madabbui-hu-si, yaisi u=ddza-kana-ggi-hu. } \\
& \text { NOM=man REFL=car fix-PFV-SEQ PTC 3SG.ACC=IP.fingers-grab-APPL-PFV } \\
& \text { 'The man fixed his car, and then he started it.' (elicitation, EM, BP50-1-s, 1) }
\end{aligned}
$$




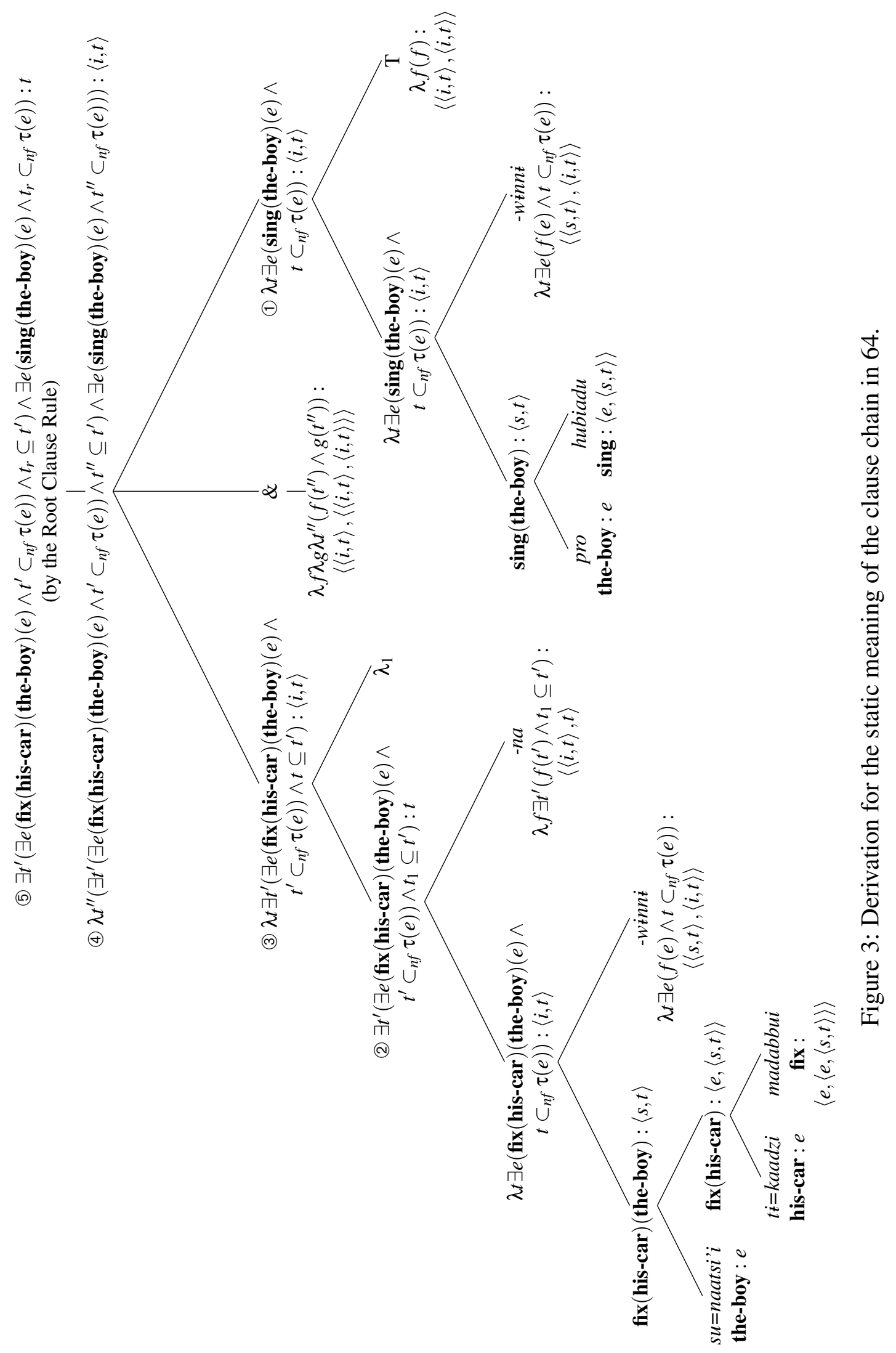


For reasons of space, I do not provide a complete semantic derivation for this sentence. But its final translation is given below.

$$
\begin{aligned}
& \exists t^{\prime}\left(\exists e\left(\mathbf{f i x}(\text { his-car })(\text { the-man })(e) \wedge \neg \exists e^{\prime}\left(e \subset e^{\prime} \wedge \text { fix }(\text { his-car })(\text { the-man })\left(e^{\prime}\right)\right) \wedge \tau(e) \subseteq t^{\prime}\right) \wedge t^{\prime}<t_{r}\right) \wedge \\
& \quad \exists e\left(\operatorname{start}(\text { his-car })(\text { the-man })(e) \wedge \neg \exists e^{\prime}\left(e \subset e^{\prime} \wedge \operatorname{start}(\text { his-car })(\text { the-man })\left(e^{\prime}\right)\right) \wedge \tau(e) \subseteq t_{r}\right)=65
\end{aligned}
$$

After the Root Clause Rule applies, the entire clause chain is true at some time interval provided by the context just in case: (i) that time is located after a time that includes the event of the man fixing his car, and (ii) it includes the event of the man starting his car. In other words, it is true just in case the event described by the marked clause temporally precedes the event described by the unmarked clause.

I have used semantic binding - abstraction over the free time variable introduced by the simultaneous or sequential suffix - to identify the evaluation time of the marked clause with the reference time of the unmarked clause. There is an alternative. While dynamic semantics is sometimes only used to represent the effect of a sentence on context, Bittner (2001, 2011, 2014) argues that sentence-internal semantic composition can be treated dynamically as well. More or less all meaningful expressions in a sentence would update the context of interpretation for subsequent expressions in the sentence. Accordingly, Bittner treats the relations between expressions, including semantic binding, as a type of anaphora.

Under such a dynamic approach, there must be operations that make certain anaphoric relations obligatory. One of these is the topic-comment sequencing operation (Bittner 2001:143, 2011:162, 2014:45f.). When certain conditions are met, it reduces to the ordinary sequencing of sentences, i.e. composition of relations. Roughly speaking, for two expressions $A$ and $B$, the topic-comment sequence of $A$ and $B$ is identical to the sequence of $A$ and $B(A ; B)$ if: (i) $A$ introduces a topical discourse referent, (ii) $B$ does not introduce another more topical discourse referent, and (iii) an anaphor inside $B$ refers to the discourse referent introduced by $A$. If any of these conditions is not satisfied, the context is reduced to the absurd state, which results in ungrammaticality. So, for instance, if $A$ introduces a topical discourse reference, but no anaphor inside $B$ refers to it, then the complex expression $A B$ is ungrammatical.

It is clear how Bittner's topic-comment sequencing operation can derive the semantics of clause chaining in Northern Paiute. Rather than introducing a free variable that must be abstracted over, the simultaneous and sequential suffixes would introduce a new topical time interval that is either included in or follows the reference time of the marked clause. The topic-comment sequencing operation would then require the reference time of the unmarked clause to take this topical time interval as its antecedent. If it were anaphoric to some other time interval instead, the third condition of the topic-comment sequencing operation would not be satisfied.

Bittner's topic-comment sequencing operation is designed to cover the same empirical ground as semantic binding. Consequently, I think it will be difficult to identify empirical arguments for or against it just by examining one language. As I explore the predictions of my own semantic binding account for clause chaining in Northern Paiute, I will sketch how a dynamic account like Bittner's might deal with them. But the semantic binding account does make typological predictions that are different from such a dynamic account, which I will also discuss as we go forward. 


\subsection{When the marked clause follows the unmarked clause}

As we saw in Section 1.3, the marked clause not infrequently follows the unmarked clause. Under my semantic binding account, the marked clause should have the same temporal interpretation relative to the unmarked clause regardless of linear order. When a marked clause that follows contains the simultaneous suffix, it is interpreted as temporally overlapping with the unmarked clause $(67 \mathrm{a}-\mathrm{b})$. More strikingly, when it contains the sequential suffix, the marked clause still temporally precedes the unmarked clause $(68 \mathrm{a}-\mathrm{b})$.

(67) a. Yaisi ka=ggwitua tiggwisu tí=ddzoti’'a ddiggwa'ni mani-kati, yaa paa'a-we PTC ACC=pail still REFL=hat look.like do-sit.IMPF there water-LOC kati-na. sit-SIM

'He still has the pail on his head that looks like a hat, while sitting in the water.' (prompted narrative, MS, BP24-1-t3, 42)

b. Yaa=bino'o moko ddakwi-ggwaddi, mi=naatsi'i wotui-na. there=PTC shoe sit.DL.IMPF-DL PL=boy wait-SIM

'The shoes are sitting there, waiting for the boys.' (prompted narrative, MS, BP24$1-\mathrm{t} 3,98)$

a. Yaisi yaa su=hibbi tihidda mia-hu, umi-ma sie-hu-si.

PTC there NOM=thing deer go-PFV 2/3PL.ACC-LOC get.scared-PFV-SEQ

'The deer left because it got scared of them.' (prompted narrative, EM, BP25-2-t1, 93-95)

b. Yaisi pisa=ga ha'o mi=igwi načodau umi ti=tua-mi

PTC good=MOD how 2/3PL.ACC=smell tracks 2/3PL.ACC REFL=child-PL

na-koi-si $[\ldots]$

PASS-kill.PL-SEQ

'Then she could really smell them, that her children were killed[...]' (narrative, Thornes|2003:496)

In 68a, the event of the deer getting scared (by the boy and dog) precedes the event of it leaving. Similarly, in $68 \mathrm{p}$, the event of the mother bear's children getting killed precedes the event of her smelling them and their tracks.

Without going through a complete semantic derivation, the clause chain in $68 \mathrm{a}$ has the following final translation, after the Root Clause Rule applies.

$$
\begin{aligned}
& \left.\exists e\left(\text { go }(\text { the-deer })(e) \wedge \neg \exists e^{\prime}\left(e \subset e^{\prime} \wedge \text { go (the-deer }\right)\left(e^{\prime}\right)\right) \wedge \tau(e) \subseteq t_{r}\right) \wedge \\
& \left.\exists t\left(\exists e(\text { get-scared (the-deer) })(e) \wedge \neg \exists e^{\prime}\left(e \subset e^{\prime} \wedge \text { get-scared }(\text { the-deer })\left(e^{\prime}\right)\right) \wedge \tau(e) \subseteq t\right) \wedge t<t_{r}\right)=68
\end{aligned}
$$

Even though the marked clause follows the unmarked clause in linear order, the entire sentence is true for some time interval provided by context just in case: (i) that time includes the event of the deer leaving, and (ii) it follows a time that includes the event of the deer getting scared. In other words, it is true just in case the event of the deer getting scared precedes the event of the deer leaving.

This noniconic temporal interpretation is an entailment. Clause chains are judged as true only when the event described by a marked clause bearing the sequential suffix precedes the event 
described by the unmarked clause in time, regardless of whether it precedes $(70 \mathrm{a})$ or follows $(70 \mathrm{p})$ in linear order. (Speakers were asked to provide truth value judgments for the sentences below with respect to the state of affairs depicted in Figure 2.)

(70) a. Su=pa'mogo wadzi-mia-hu-si, su=naatsi'i tibuni-hu. NOM=frog hide-go-PFV-SEQ NOM=boy wake.up-PFV

'After the frog escaped, the boy woke up.' (elicitation, EM, BP38-2, 18:16)

b. $\quad \mathrm{Su}=$ naatsi'i tibuni-hu, su=tiitsi-'yu pa'mogo wadzi-mia-hu-si. NOM=boy wake.up-PFV NOM=little-NOM frog hide-go-PFV-SEQ

'After the little frog escaped, the boy woke up.' (elicitation, EM, BP42-7-s, 8)

c. \# Su=naatsi'i tibuni-hu-si, su=pa'mogo wadzi-mia-hu. NOM=boy wake.up-PFV-SEQ NOM=frog hide-go-PFV

Intended: 'After the frog escaped, the boy woke up.' (elicitation, MS, BP38-2, 19:16)

[MS: "No, that would be after he woke up, but this is when he went to sleep."]

d. \# Su=pa'mogo wadzi-mia-hu, su=tiitsi-'yu naatsi'i tibuni-hu-si. NOM=frog hide-go-PFV NOM=little-NOM boy wake.up-PFV-SEQ Intended: 'After the frog escaped, the little boy woke up.' (elicitation, EM, BP43-4, 22:39)

[EM: "If he was awake and the frog left, then you could say that."]

When the marked clause instead describes the event of the boy waking up — which in the context provided temporally follows the event of the frog escaping - speakers judge the clause chain false, whether the linear order is iconic $(70 \mathrm{~d})$ or not $(70 \mathrm{c})$.

How could a dynamic account that uses the topic-comment sequencing operation deal with this variation in the linear position of the marked clause? Bittner (2001:129) proposes that there is a universal context-setting order in which heads are interpreted before - and hence set up the context for - their dependents. She acknowledges, however, that there are some exceptions. Certain dependents (so-called TOP-dependents) set up the context for their heads because they are better topics, e.g. temporal adjunct clauses. Even though the marked clause is not a dependent of the unmarked clause - as we saw in Section 1, clause chaining in Northern Paiute has a coordination structure - it does not seem unreasonable to analyze it in the same way. Thus, regardless of its linear order, the marked clause can be interpreted first, so that it updates the context before the unmarked clause is interpreted.

However, this dynamic account will have to deal with the fact that while linear order does not matter for some aspects of the temporal interpretation of clause chaining, it does matter for others. In particular, as I will discuss in Section 4, the semantics that I have been developing for clause chaining must be enriched by principles for the temporal interpretation of sentences in discourse (Kamp and Rohrer 1983, Partee 1984, Hinrichs 1986). These are sensitive to the linear position of the marked clause. In a narrative, when the marked clause precedes the unmarked clause, it receives a 'forward moving' interpretation that is not present when it follows the unmarked clause in linear order. While I do not think this is an insurmountable problem for the dynamic approach, my account using semantic binding makes the right cut between the order-insensitive and ordersensitive meaning components of clause chaining without saying anything more. 
In addition, the semantic binding and dynamic accounts make different predictions about the crosslinguistic typology of clause chaining. Under my proposal, anytime a tenseless language has clause chaining with a coordination structure, then the marked clause should be able to either precede or follow the unmarked clause in linear order and still give rise to the same meaning. In contrast, the dynamic approach makes no such prediction, since it does not obviously relate these properties to one another in any way. The topic-comment sequencing operation and contextsetting order for interpreting expressions are presumably universals, and neither has any bearing on whether a language has absolute tense or not. If further crosslinguistic investigation confirms the implicational universal above, it would be important evidence for semantic binding.

\subsection{When there are multiple marked clauses}

When there is more than one clause in a chain marked with the sequential suffix, speakers report that the marked clauses are temporally related not just to the unmarked clause but also to one another.

$\begin{array}{lllr}\text { a. Nimmi } & \text { puggu tinoo-ggi-si, } & \text { u=hibi-ggi-si, } & \text { mia-hu. } \\ \text { 1PL.EXCL.NOM horse pack-APPL-SEQ } & \text { 3SG.ACC=drink-APPL-SEQ go-PFV }\end{array}$

'We packed up the horses, and then we watered them, and then we left.' (elicitation, EM, BP44-2, 14:20)

[MT: "What happened first?[...]" EM: "Pack the horses. Then you gave them water, and then you left."]

b. Nimmi puggu hibi-ggi-si, u=ddinoo-ggi-si, mia-hu. 1PL.EXCL.NOM horse drink-APPL-SEQ 3SG.ACC=pack-APPL-SEQ go-PFV

'We watered the horses, and then we packed them up, and then we left.' (elicitation, EM, BP44-2, 16:12)

[EM: "You fed'em first, and then you pack it, and then you..."]

In 71 , the event of packing the horses described by the first marked clause is interpreted as temporally preceding the event of watering them described by the second marked clause. When the linear order of the two marked clauses is reversed, as in $71 \mathrm{p}$, the temporal relation between them is also reversed.

Under the semantics I have proposed, however, both $71 \mathrm{a}$ and $71 \mathrm{~b}$ have the same entailments. While each marked clause must temporally precede the unmarked clause, there is no temporal relation imposed between the marked clauses themselves.

$$
\begin{aligned}
& \left.\exists t\left(\exists e\left(\text { pack }(\text { the-horses })(\text { we })(e) \wedge \neg \exists e^{\prime}\left(e \subset e^{\prime} \wedge \text { pack(the-horses }\right)(\text { we })\left(e^{\prime}\right)\right) \wedge \tau(e) \subseteq t\right) \wedge t<t_{r}\right) \wedge \\
& \left.\exists t^{\prime}\left(\exists e\left(\text { water (the-horses) }(\text { we })(e) \wedge \neg \exists e^{\prime}\left(e \subset e^{\prime} \wedge \text { water(the-horses }\right)(\text { we })\left(e^{\prime}\right)\right) \wedge \tau(e) \subseteq t^{\prime}\right) \wedge t^{\prime}<t_{r}\right) \wedge \\
& \exists e\left(\text { take-off }(\text { we })(e) \wedge \neg \exists e^{\prime}\left(e \subset e^{\prime} \wedge \text { take-off }(\text { we })\left(e^{\prime}\right)\right) \wedge \tau(e) \subseteq t_{r}\right) \quad=71 \mathrm{a}-\mathrm{b}
\end{aligned}
$$

The evaluation time of each marked clause is identified with the reference time of the unmarked clause. In the final translation of this sentence, the entire clause chain is true at some time interval provided by context just in case: (i) that time includes the event described by the unmarked clause, and (ii) for each marked clause, it follows a time that includes the event described by that marked clause.

This relatively weak meaning is necessary to account for clause chains in which two marked clauses containing the sequential suffix overlap in their temporal interpretation. 
a. O'o-no yaisi una-tu kwaya mia-si, sogo-mia-si, una-u DEM-with PTC DEM-LOC far go-SEQ on.foot-go-SEQ DEM.ACC-EMPH yaisi uuni-kwai piti-ga na-tihona-di-kwai. PTC that.kind-LOC arrive-MOT PASS-dig.roots-NMLZ-LOC

'So then it was that they went far off, going on foot, and arrived there at the root digging place.' (narrative, Thornes 2003:486)

b. Yaa hibbi-ggwe-tu paba tiipi hani-si, o=wi-taggi-si, there place-LOC-LOC big earth do-SEQ 3SG.ACC=IP.long-make.hole-SEQ yaisi oi-tu painitsi oi-tu wokwati-kwi. PTC there-LOC pinenuts there-LOC dump-IRR

'At that place, after we dig a lot of dirt and we make a big hole in the ground, then we will dump the pinenuts in there.' (elicitation, EM, BP13-4-t9, 5)

In 73 , the first marked clause describes an event of leaving, which overlaps with the second marked clause, which describes an event of leaving on foot. Rather than occurring in a temporal sequence, the second marked clause elaborates on the first marked clause by adding more detail. Similarly, in $73 \mathrm{~b}$, the second marked clause does not describe an event that temporally follows the event described by the first marked clause; it simply contributes additional information about how the hole digging happened.

This can also be shown more directly. Speakers judge clause chains like the one in 74 a true, even when the events described by two marked clauses overlap temporally.

(74) Context: The boy and girl are at home. Instead of studying, he is playing and she is dancing at the same time. They both stop before their mother comes home.

a. Su=naatsi'i ti'tia-hu-si, su=tsia'a niga-hu-si, su=mogo'ni NOM=boy play-PFV-SEQ NOM=girl dance-PFV-SEQ NOM=wOman nobi-ggwe iga-hu. house-LOC enter-PFV

'After the boy played and the girl danced, the woman came home.' (elicitation, EM, BP53-3, 51:12)

[EM: "They probably doing that when the lady was not there[... ]at the same time. Then she came in after they were through."]

b. Su=tsia'a niga-hu-si, su=naatsi'i ti'tia-hu-si, su=mogo'ni nobi-ggwe NOM=girl dance-PFV-SEQ NOM=boy play-PFV-SEQ NOM=woman house-LOC iga-hu.

enter-PFV

'After the girl danced and the boy played, the woman came home.' (elicitation, EM, BP53-3, 54:00)

[EM: "They mean the same thing."]

Importantly, the liner order of the marked clauses does not matter. Speakers also judged the clause chain in $74 \mathrm{~b}$ true, since it has the same entailments as the one in 74a.

Under a dynamic account with the topic-comment sequencing operator, it should be possible to derive this relatively weak semantics for clause chaining in Northern Paiute. Presumably, when 
a sentence contains more than one temporal adjunct clause, there is some way of relating both of them to the main clause, e.g. After the motion was made, after it was seconded, the senators voted. Like these temporal adjunct clauses, each marked clause in a chain would introduce a time interval that would be able to serve as the antecedent of the reference time in the unmarked clause.

The semantic binding account does, however, make a prediction that the dynamic account does not. If a tenseless language has clause chaining with a coordination structure, then marked clauses should only be related semantically to the unmarked clause. In contrast, the dynamic account makes no such prediction. Whatever mechanism is responsible for ensuring the relatively weak semantics for clause chaining attested in $73+74$ is presumably available in any language. Hence, it could not be dependent on whether a language has absolute tense or whether it has clause chaining with a coordination structure.

\section{Interpreting clause chaining in discourse}

As we just saw, the semantics that I have proposed for clause chaining in Northern Paiute only accounts for part of its temporal interpretation. By abstracting over the evaluation time in the marked clause, a temporal relation is established between it and the unmarked clause. But often there is more to the meaning of a clause chain; this is especially clear when it contains more than one marked clause.

$\begin{array}{lll}\text { Nimmi puggu tinoo-ggi-si, u=hibi-ggi-si, mia-hu. } & \text { u } \\ \text { 1PL.EXCL.NOM horse pack-APPL-SEQ } & \text { 3SG.ACC=drink-APPL-SEQ go-PFV }\end{array}$

'We packed up the horses, and then we watered them, and then we took off.' (elicitation, EM, BP44-2, 14:20)

[MT: "What happened first?[... ]" EM: "Pack the horses. Then you gave them water, and then you left."]

In this example, repeated from 71 above, the marked clauses are related to one another temporally, not just to the unmarked clause. The event described by the second marked clause is interpreted as taking place immediately after the event described by the first marked clause. In addition, the unmarked clause is related temporally to the preceding clause in a way that goes beyond the entailments of the sentence. The event described by the unmarked clause does not just follow the event described by the second marked clause - it takes place immediately after it.

I propose that this enriched meaning arises from more general principles for the temporal interpretation of sentences in discourse. In particular, when sentences are understood as comprising a narrative, they are interpreted as 'forward moving.' A sequence of sentences containing telic predicates - either achievements or accomplishments - in the perfective aspect are interpreted as taking place in close temporal succession (Kamp and Rohrer 1983, Partee 1984, Hinrichs 1986).

Jameson entered the room. He shut the door. He switched off the light.

(after Hinrichs 1986:68)

In this narrative, the event of Jameson switching off the light is interpreted as taking place immediately after the event of him shutting the door, which is itself interpreted as taking place immediately after the event of him entering the room. In Northern Paiute, a sequence of sentences in a narrative discourse can receive the same forward moving interpretation. 
Nimmi ka=puggu tinoo-ggì-hu. U=hibi-ggi-hu. Mia-hu.

1PL.EXCL ACC=horse pack-APPL-PFV 3SG.ACC=drink-APPL-PFV go-PFV

'We packed the horse. We watered it. We left.' (elicitation, MS, BP53-3, 1:35)

[MS: 'You loaded the horses, and then you gave it drink. Then you went."]

In 77, the event of leaving is interpreted as taking place immediately after the event of watering the horse, which is itself interpreted as taking place immediately after the event of loading the horse.

Importantly, the discourse principles that ensure narrative progression cannot all by themselves account for the temporal interpretation of clause chaining. The temporal relation between a marked clause and the unmarked clause must still be derived compositionally through semantic binding. As I argued in Section 3.2, the sequential suffix entails that the event described by the marked clause temporally precedes the event described by the unmarked clause, regardless of their linear order. Without this semantic contribution, the clauses in a chain would always receive a temporal interpretation that was iconic. That is, when a marked clause containing the sequential suffix followed the unmarked clause in linear order, it would be interpreted - incorrectly — as following it in time as well.

To account for the interpretation of clause chaining in discourse, I move in Section 4.1 to a dynamic semantics that builds on the static semantics I have already laid out. In particular, I adopt Muskens's (1995) logic of change, since it permits a compositional treatment of clause chaining that leaves room for information added by general principles for the interpretation of sentences in discourse. In Section 4.2, I show that my account correctly predicts how each clause in a chain is temporally related to the preceding discourse. Then, in Section 4.3, I return to the clause chain with more than one marked clause in 75. Its enriched meaning in a narrative arises because each marked clause is interpreted as taking place immediately after the preceding clause. Finally, in Section 4.4, I address how clause chains in which the marked clause follows the unmarked clause are interpreted in discourse.

\subsection{Introducing the logic of change}

To represent the forward moving temporal interpretation of narrative discourse, a sentence can be interpreted as taking place immediately after a contextually provided REFERENCE POINT, in Kamp and Reyle's (1993) terms. The reference point is not located just anywhere in the preceding discourse. While the second sentence in 77 is interpreted as taking place immediately after the first sentence, the final sentence does not have the same reference point. It is interpreted as taking place immediately after the second sentence. This means that the reference point is shifted throughout the course of a discourse.

I adopt Muskens (1995) logic of change to represent this dynamically changing reference point. It assumes context states as primitive objects, in addition to individuals, truth values, times intervals, and events. Sentences express a relation between context states. The items that conversational participants keep track of in discourse - and whose value can be updated as the context changes - are STORES, or functions from states to individuals, time intervals, or events. One store is particularly important here, the reference point or $R$, which I assume is a function from context states to time intervals. 


\section{Updating the reference point}

How does the reference point shift as the sentences in a discourse are interpreted? To start, building on Kamp and Reyle (1993:523) and Kamp et al. (2011:204), I assume that the value of $R$ can only be updated to the reference time of some sentence in the discourse. In 77, once each sentence has been interpreted relative to the then-current reference point, it is reset to be equivalent to the reference time of that sentence. So, the second sentence is interpreted immediately after the reference time of the first sentence, while the third sentence is interpreted immediately after the reference time of the second sentence.

Aspect plays a crucial role in updating the reference point. The sentences in 77, which shift it forward, are all in the perfective aspect. The imperfective aspect does not reset the reference point. For instance, the third sentence in 78, which describes the event of Josef firing his weapon, is interpreted as taking place immediately after the event of him turning around, which is described by the first sentence. The intervening sentence in the progressive aspect does not move the reference point at all. In addition, as I will discuss shortly, it is interpreted as temporally overlapping with the previous sentence.

(78) Josephine turned around. The thief was fumbling in his bag. She fired her gun.

(79) His boss tried to turn the doorknob. The door was locked. She opened it with her key.

In English, atelic predicates in the perfective aspect exhibit the same behavior. In 79, the second sentence, which contains a stative predicate, does not update the reference point, so that the third sentence is interpreted as taking place immediately after the first sentence.

In Northern Paiute, the imperfective aspect similarly does not update the reference point. In 80 . the second sentence contains the progressive suffix and describes an event of playing that overlaps with the event described by the first sentence. Importantly, as the speaker's comments indicate, the third sentence is interpreted as taking place immediately after the first sentence.

(80) $S u=m o g o ' n i \quad$ nobi-ggwe iga-hu. Su=naatsi'i ti'atia-winni. Su=mogo'ni

NOM=woman house-LOC enter-PFV NOM=boy play-PROG NOM=woman $\mathrm{u}=$ haa-hu.

3SG. ACC $=$ scold-PFV

'The woman came into the house. The boy was playing. The woman scolded him.' (elicitation, EM, BP53-3, 20:45)

[EM: "He probably was playing in the house. Then the woman come in and then she bawl him out."]

(81) $\mathrm{Su}=$ mogo'ni nobi-ggwe iga-hu. $\mathrm{Su}=$ naatsi'i ti'atia-hu. Su=mogo'ni

NOM=woman house-LOC enter-PFV NOM=boy play-PFV NOM=woman

$\mathrm{u}=$ haa-hu.

3SG. ACC $=$ scold $-\mathrm{PFV}$

'The woman came into the house. The boy finished playing. The woman scolded him.' (elicitation, EM, BP53-3, 25:35)

[EM: "She bawled him out when he quit playing, I guess."] 
However, atelic predicates in the perfective in Northern Paiute pattern just like telic predicates.$^{10}$ In 81 , the event of the woman scolding the boy described by the third sentence takes place immediately after the event of the boy playing described by the second sentence. This is not surprising given the semantics of the perfective suffix in Northern Paiute, which entails event termination (see Section 2.1).

To capture this contrast between perfective and imperfective aspect in Northern Paiute, I propose the following dynamic lexical entries for the progressive and perfective suffixes. There must also be phonologically null Asp heads with the same meanings. (I continue to abbreviate the type of sentences as $t$, even though they denote relations between context states.)

$$
\begin{aligned}
& \text { The semantics of the progressive suffix (dynamic version) } \\
& \llbracket \text {-winni } \rrbracket=\lambda f \lambda t \lambda i \lambda j \exists e\left(f(e)(i)(j) \wedge t \subset_{n f} \tau(e) \wedge i=j\right):\langle\langle s, t\rangle,\langle i, t\rangle\rangle
\end{aligned}
$$

The semantics of the perfective suffix (dynamic version)

$$
\begin{aligned}
\llbracket \text {-hu } \rrbracket & \lambda f \lambda t \lambda i \lambda j \exists e\left(f(e)(i)(j) \wedge \neg \exists e^{\prime}\left(e \subset e^{\prime} \wedge f\left(e^{\prime}\right)(i)(j)\right) \wedge \tau(e) \subseteq t \wedge i[R] j \wedge\right. \\
& R(j)=t):\langle\langle s, t\rangle,\langle i, t\rangle\rangle
\end{aligned}
$$

The perfective suffix resets the reference point, so that its value in the output state $(R(j))$ is the reference time. (A formula of the form $i[v] j$ says that all stores except $v$ return the same value for context states $i$ and $j$.) In contrast, the progressive suffix, which conveys a type of imperfective aspect, does not update the reference point.

\section{The temporal relation with the reference point}

Narrative progression arises, then, because perfective aspect updates the reference point. But we still need some way to represent the temporal relation between a sentence and the then-current reference point. I follow Kamp et al. (2011:203-207) in assuming that every clause presupposes an underspecified temporal relation $(\rho)$ between its reference time and the reference point of the input state. For concreteness, this relation can be encoded in the lexical entry for T; I do not represent its status as a presupposition.

$$
\llbracket \mathrm{T} \rrbracket=\lambda f \lambda t \lambda i \lambda j(f(t)(i)(j) \wedge \rho(R(i), t)):\langle\langle i, t\rangle,\langle i, t\rangle\rangle
$$

It is not just the $\mathrm{T}$ head in an unmarked clause or independent sentence that introduces this presupposition. The simultaneous and sequential suffixes, which I have argued are also members of $\mathrm{T}$, presuppose the same underspecified temporal relation between the reference time of the marked clause and the then-current reference point.

$$
\begin{aligned}
& \text { The semantics of the simultaneous suffix (dynamic version) } \\
& \llbracket \text {-na }=\lambda f \lambda i \lambda j \exists t\left(f(t)(i)(j) \wedge t_{1} \subseteq t \wedge \rho(R(i), t)\right):\langle\langle i, t\rangle, t\rangle \\
& \text { The semantics of the sequential suffix }(\text { dynamic version) } \\
& \llbracket \text {-si } \rrbracket=\lambda f \lambda i \lambda j \exists t\left(f(t)(i)(j) \wedge t<t_{1} \wedge \rho(R(i), t)\right):\langle\langle i, t\rangle, t\rangle
\end{aligned}
$$

The $\rho$ relation must be underspecified because the temporal relation between a clause and the reference point is not constant. In narrative discourse, the $\rho$ relation is filled in with different values depending on the aspect of the clause.

\footnotetext{
${ }^{10}$ This is shown for the activity hubiadu 'sing' in 81 . Northern Paiute does have stative verbs, but these are cooerced into an inceptive, and hence telic, interpretation in the perfective aspect.
} 
(i) if $S$ is in the perfective aspect, $t^{\prime}$ is located 'immediately after' $t$, i.e. $t \ll t^{\prime}$, or

(ii) if $S$ is in the imperfective aspect, $t$ is properly included in $t^{\prime}$, i.e. $t \subset t^{\prime}$.

In Northern Paiute, for a clause in the perfective aspect, the $\rho$ relation is specified as immediate temporal precedence $(\ll)$, since the event it describes is interpreted as taking place immediately after the then-current reference point. In contrast, as we saw in 80 , for a clause in the imperfective aspect, the event it describes can overlap with the then-current reference point (though see Dowty 1986). So, the $\rho$ relation is instead specified as proper temporal inclusion $(\subset)$.

Importantly, the principles in 87 do not extend to every discourse, since narrative progression is only a default (Lascarides and Asher 1993). When sentences do not constitute a narrative, they are interpreted with different temporal relations.

$$
\text { Max fell. John pushed him. }
$$

$$
\text { Chris had a fantastic meal. He ate salmon. }
$$$$
\text { (Kamp et al. 2011,207) }
$$

In 88, the second sentence is the explanation for the first sentence, and consequently the pushing event is interpreted as preceding the falling event. In contrast, in 89, the second sentence is an elaboration of the first sentence; the event of eating salmon is interpreted as overlapping the event of having a fantastic meal. ${ }^{11}$ In Northern Paiute, too, narrative progression is only the default.

$\mathrm{Su}=$ naatsi'i habi-hu. $\mathrm{Su}=$ tsia'a u=dda-tsa-kwiba-ggi-hu.

NOM=boy fall-PFV NOM=girl 3SG.ACC=IP.foot-IP.fingers-hit-APPL-PFV

'The boy fell. The girl tripped him.' (elicitation, EM, BP53-3, 11:15)

[EM: "She tripped him first, and then he fell down."]

$\mathrm{Su}=$ nana nobi-ggwe-tu mia-hu. Sogo-mia-hu.

NOM=man house-LOC-LOC go-PFV on.foot-go-PFV

'The man left to go home. He left on foot.' (elicitation, MS, BP53-3, 16:10)

[MS: "He went home, and he walked[... ]instead of going in a taxi or car."]

In 90 , because the second sentence is the explanation for the first sentence, the tripping event is interpreted as preceding the falling event. In 78, the second sentence is an elaboration of the first sentence, and they describe events that overlap.

I will not attempt here to state how conversational participants figure out what the temporal relations between sentences are in nonnarrative discourse. It should never be possible to fill in the $\rho$ relation so that it contradicts an entailment of the sentence. But beside this, the question of how it is specified is a complex one, whose answer likely depends on numerous different factors, including rhetorical relations and world knowledge (Moens and Steedman 1988, Hobbs 1979, Hobbs et al. 1993, Kehler 2002, Asher and Lascarides 2003). For our purposes, the principles for the interpretation of narrative discourse in 87 are enough.

\footnotetext{
${ }^{11}$ Bittner (2008:358) suggests that all discourses are actually forward moving (see also Webber 1988:66). English verbs are simply 'underspecified for aspectual type,' so that fall in 88 describes the preparatory stage before an instantaneous change of state. She argues that Kalaallisut, as an 'aspectually explicit' language, does not permit noniconic temporal interpretation in discourse. I think that something more must be going on here. Like Kalaallisut, Northern Paiute makes the relevant aspectual distinctions explicit, and yet it only has narrative progression as a default.
} 


\section{A dynamic semantics for asyndetic coordination}

We have so far only considered how independent sentences are interpreted in discourse. But clauses coordinated by and in English are related temporally to the reference point in the same way. The discourses in 92 and 93 are parallel to the discourses containing three independent sentences in 78 and 79, respectively.

Jameson entered the room. He shut the door, and he switched off the light.

Josephine turned around. The thief was fumbling in his bag, and she fired her gun.

In 92, the first clause in the coordination structure is interpreted as taking place immediately after the preceding sentence; it also updates the reference point for the second coordinate. Similarly, in 93. the first clause in the coordination is interpreted as overlapping temporally with the preceding sentence. The second coordinate is interpreted as taking place immediately after it. 12

In this respect, coordination can be contrasted with subordination structures created by after or while. In a narrative, the event described by a temporal adjunct clause need not overlap with or occur immediately after the then-current reference point. Rather, it is interpreted relative to some subsequent time (Partee 1984;257-265, Hinrichs 1986:73-77).

(94) a. Mary turned the corner. While the cars were stopped, she crossed the street.

b. Mary turned the corner. After John saw her, she crossed the street.

The state of the cars being stopped described by the temporal adjunct clause in 94 a does not overlap with, or even immediately follow, the event of Mary turning the corner. Similarly, the event of John seeing Mary described by the temporal adjunct clause in $94 \mathrm{p}$ does not have to immediately follow the then-current reference point.

For these and other reasons, the conjunction of clauses can be treated within a dynamic semantics like the sequencing of independent sentences, i.e. composition of relations (Groenendijk and Stokhof 1991:44-48). Following Muskens's (1996:176-182) schema for generalized dynamic conjunction, I adopt the following lexical entry for asyndetic coordination in Northern Paiute.

$$
\begin{aligned}
& \text { The semantics of asyndetic coordination (dynamic version) } \\
& \llbracket \& \rrbracket=\lambda f \lambda g \lambda t \lambda i \lambda j \exists k(f(t)(i)(k) \wedge g(t)(k)(j)):\langle\langle i, t\rangle,\langle\langle i, t\rangle,\langle i, t\rangle\rangle\rangle
\end{aligned}
$$

Since the first clause is interpreted with respect to the input state, it will be temporally related to the then-current reference point, as determined by the preceding discourse. In addition, the output state for the first coordinate serves as the input for the second coordinate, so that the reference point can be shifted across the clauses in a coordination structure.

\subsection{The relation to the preceding discourse}

To put these pieces together, consider the basic example of clause chaining from $48 \mathrm{~b}$ above; there is just one marked clause containing the simultaneous suffix.

\footnotetext{
${ }^{12}$ While the coordination structures in 92,93 have the same temporal interpretations as the parallel sequences of independent sentences, it is sometimes argued that the coordinator and in English restricts the temporal relations that are possible between its coordinates (Bar-Lev and Palacas 1980, Gómez Txurruka 2003).
} 
Su=naatsi' $i$ tí=kaadzi madabbui-winni-na, yaisi hubiadu-winni.

NOM=boy REFL=car make-PROG-SIM PTC sing-PROG

'The boy is fixing his car and singing.' (elicitation, EM, BP50-1, 9:19)

The complete derivation of the dynamic meaning for this sentence is given in Figure 4 . The unmarked clause is a function from times to relations between context states (1). The marked clause has the same type, after abstraction over the free time variable introduced by the simultaneous suffix (2). With the lexical entry for asyndetic coordination above, the output state of the marked clause serves as the input state with respect to which the unmarked clause is interpreted (3)). (Recall from footnote 8 that I am assuming a compositional rule for coordination structure that is sensitive to the linear order of coordinates.)

The final translation for 96 is repeated below, with the underspecified temporal relation $\rho$ filled in according to the principles in 87 . In both the marked and unmarked clauses, it is equivalent to proper temporal inclusion $(\subset)$ because they are in the imperfective aspect.

$$
\begin{gathered}
\lambda i \lambda j \exists k\left(\exists t^{\prime}\left(\exists e(\text { fix (his-car) (the-boy) })(e)(i)(k) \wedge t^{\prime} \subset_{n f} \tau(e) \wedge i=k\right) \wedge t_{r} \subseteq t^{\prime} \wedge \underline{\left.R(i) \subset t^{\prime}\right) \wedge}\right. \\
\quad\left(\exists e(\text { sing (the-boy })(e)(k)(j) \wedge t_{r} \subset_{n f} \tau(e) \wedge k=j\right) \wedge \underline{\left.\left.R(k) \subset t_{r}\right)\right)}
\end{gathered}
$$

The presupposition of the marked clause - the first underlined formula - requires the reference point of the input state $(R(i))$ to be properly included in the reference time of the marked clause, and consequently to be properly included in the event of the boy fixing his car.

In other words, for a clause chain like 96, the marked clause should be interpreted as overlapping with the current reference point in a narrative. Since only the perfective aspect updates the reference point, this will be the reference time of the closest preceding perfective clause. Indeed, this is exactly what we find.

a. Ya'a yaisi su=ddoogga ka=sinabi-ma-ddi ka=nodda nobi tiggwi-ggi-hu-si, DEM PTC NOM=dog ACC=tree-LOC-LOC ACC=bee house fall-APPL-PFV-SEQ mi=nodda=bino'o ina-hu-dui, mani-winni-na. $\mathrm{PL}=$ bee $=$ PTC go.everywhere-PFV-INT do-PROG-SIM

$\mathrm{Su}=$ naatsi' $i=$ bino'o tu'i ggwati-na, tiggwisu tu'i ggwati, ti=pa'mogo. NOM=boy=PTC almost look.for-SIM still try look.for REFL=frog

Su=kiibbi=bino'o ma-ma mi=muima-ggwinni-na, NOM=prairie.dog=PTC DEM-LOC 2/3PL.ACC=peek.out-PROG-SIM sua'i.

laugh.IMPF

'The dog next to the tree made the beehive fall, and the bees went everywhere. The boy is still looking all over, looking all over for his frog. The prairie dog is peeking out at them, laughing.' (prompted narrative, MS, BP25-2-t2, 43-44) 


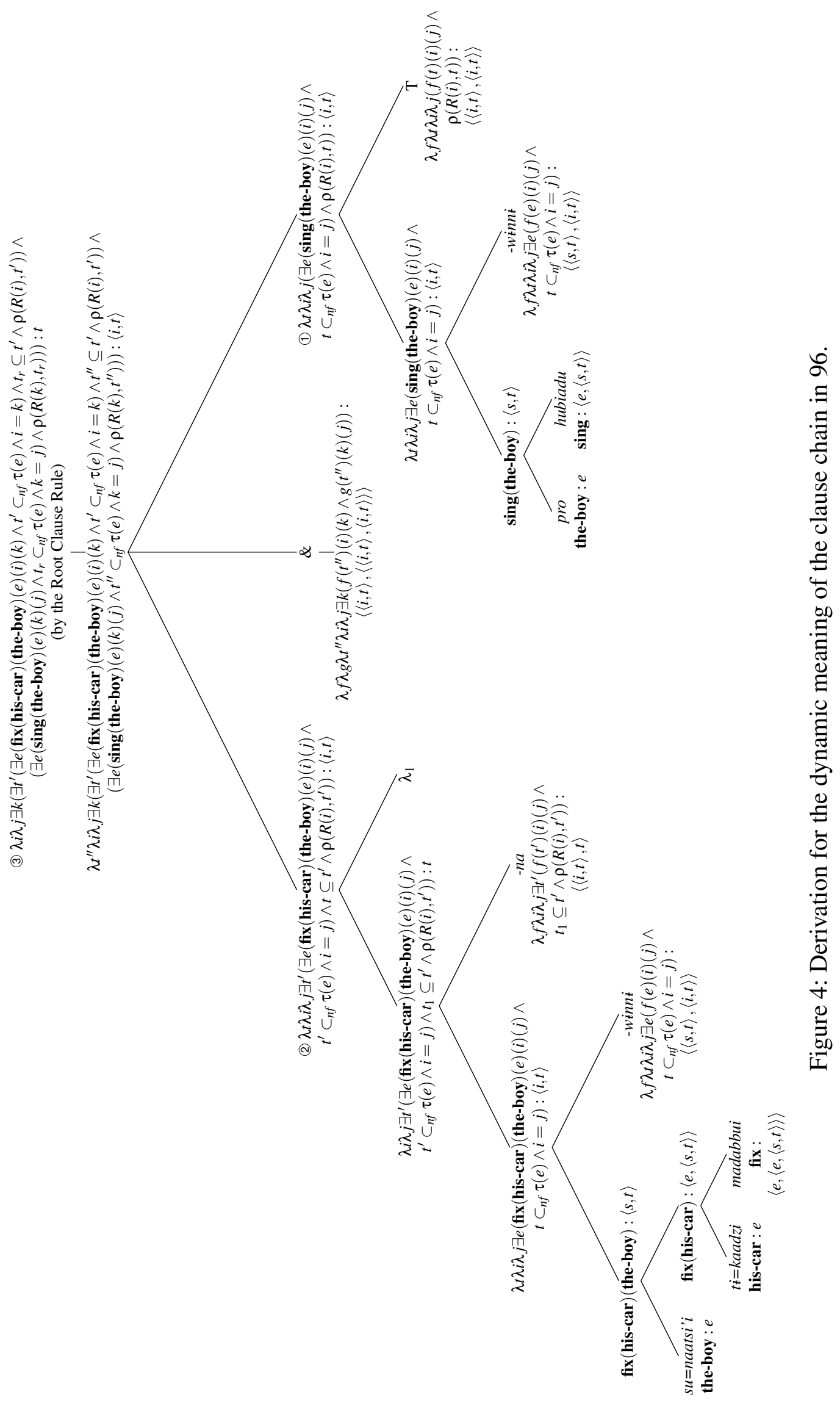


b. [...] ]yaisi su=naatsi'i ti=ddogga-tsi-no ka=pa'mogo yaa-hu. Yaa

PTC NOM=boy REFL=dog-DIM-with ACC=frog miss-PFV DEM na-ggwatima-ggwe-tu kado’o. Moko=sabbi yaa yakwi-gwaddi. Yaisi kado'o. PASS-lock-LOC-LOC nothing shoe=PTC DEM sit.DL.IMPF-DL PTC nothing Mia-pi amamu'a. Yaisi sida niimma-gwaddi-na, yaa ti=habinnu-ggwe go-PRF morning PTC bad feel-DL-SIM DEM REFL=bed-LOC $\mathrm{o}=$ bbuni-ddakwi-gwaddi.

3SG.ACC $=$ see-sit.DL-DL

'[...] the little boy and his dog realized the frog was missing. The place where he was locked up was empty. Only the shoes were sitting there. There was nothing. It had left in the morning. They were feeling bad, sitting there in their bed looking at it.' (prompted narrative, MS, BP25-2-t2, 10-13)

The narrative in 98 a was prompted using a picture book in which a boy and his dog are looking for a frog. ${ }^{13}$ In the scene described by the speaker, a prairie dog is watching them, as the dog is barking at a beehive. The marked clause describes the event of the prairie dog peeking out of its hole, which overlaps with the event of the bees going all over the place described by the closest preceding perfective clause. Similarly, in $98 \mathrm{~b}$, an excerpt from earlier in the same story, the marked clause describes the state of the boy and his dog feeling bad, which overlaps with the event of their realizing that the frog is missing.

In addition, Partee (1984:262) provides an easy way to test whether or not a sentence is interpreted at the current reference point. She observes that the discourse in $99 \mathrm{a}$ is ill formed because the second sentence is interpreted as temporally overlapping the first sentence, even though the state of the room being empty cannot hold at the same time that people begin to leave. Not surprisingly, the parallel discourse in $99 \mathrm{~b}$ is also infelicitous. The state of the room being empty is described by the first coordinate of and, which is also interpreted at the then-current reference point.

a. \# People began to leave. The room was empty. The janitors came in.

(Partee 1984,262)

b. \# People began to leave. The room was empty, and the janitors came in.

c. People began to leave. When the room was empty, the janitors came in.

(Partee 1984;262)

By contrast, the discourse in $99 \mathrm{r}$ is felicitous. As Partee observes, the state of the room being empty is described by a temporal adjunct clause; rather than overlapping with the current reference point, it is interpreted at some later time, after all the people have left.

We can use this test to confirm that the marked clause in chains like 96 is interpreted relative to the current reference point. The sequence of independent sentences in 100 a is infelicitous because the state of the wood being gone cannot hold at the same time that the fire is being made - only at a later time when the fire has burned down and just embers are left.

a. \# Niq pida-hu. Su=kuna kado'o.

1SG.NOM make.fire-PFV NOM=wood nothing

Intended: 'I made a fire. There was no wood.' (elicitation, EM, BP44-2, 1:27:50)

[EM: "Yeah, but how are you going to be making fire when you got no wood?"]

\footnotetext{
${ }^{13}$ Mercer Mayer. 1969. Frog, where are you? New York: Dial Books.
} 


\section{b. \# Nii pida-hu. Su=kuna kado'o-na, nił ka=kutsu 1SG.NOM make.fire-PFV NOM=wood nothing-SIM 1SG.NOM ACC=meat tinoho. roast.IMPF}

Intended: 'I made a fire. When there was no wood, I was roasting the meat.' (elicitation, MS, BP44-5, 5:50)

[MS: "How did you start the fire if you didn't have no wood?"]

The parallel clause chain in $100 \mathrm{p}$ is also ill formed. The marked clause is interpreted at the thencurrent reference time, but the wood cannot be gone at the same time that the fire is made.

What about the presupposition of the unmarked clause - the second underlined formula in 97? Because imperfective aspect in the marked clause does not update the reference point $-R(i)=$ $R(k)$ - the unmarked clause and marked clauses are both related to the same time interval. As a consequence, the marked clause must temporally include the same reference point as the marked clause. This relation is, of course, difficult to discern. The simultaneous suffix entails that the reference time of the unmarked clause is properly included in the reference time of the marked clause.

It is easier to see the added contribution from the presupposition of the unmarked clause when the marked clause contains the sequential suffix. Consider the clause chain below, repeated from 101 above.

$\mathrm{Su}=$ nana $\quad \mathrm{t} \dot{\mathrm{i}}=\mathrm{kaadzi}$ madabbui-hu-si, yaisi $\mathrm{u}=$ ddza-kana-ggi-hu.

NOM=man REFL=car fix-PFV-SEQ PTC 3SG.ACC=IP.fingers-grab-APPL-PFV

'After the man fixed his car, he started it.' (elicitation, EM, BP50-1-s, 1)

The final translation of this sentence, after the application of the Root Clause Rule, is given in 102. Since the marked and unmarked clauses are in the perfective aspect, the $\rho$ relation in both clauses is specified as immediate temporal precedence $(\ll)$, according to the principles in 87 .

$$
\begin{aligned}
& \lambda i \lambda j \exists \exists\left(\exists t ^ { \prime } \left(\exists e \left(\mathbf{f i x}(\text { his-car })(\text { the-man })(e)(i)(k) \wedge \neg \exists e^{\prime}\left(e \subset e^{\prime} \wedge \text { fix }(\text { his-car })(\text { the-man })\left(e^{\prime}\right)(i)(k)\right) \wedge\right.\right.\right. \\
& \left.\left.\tau(e) \subseteq t^{\prime} \wedge i[R] k \wedge R(k)=t^{\prime}\right) \wedge t^{\prime}<t_{r} \wedge R(i) \ll t^{\prime}\right) \wedge \\
& \quad\left(\exists e \left(\operatorname{start}(\text { his-car })(\text { the-man })(e)(k)(j) \wedge \neg \exists e^{\prime}\left(e \subset e^{\prime} \wedge \operatorname{start}(\text { his-car })(\text { the-man })\left(e^{\prime}\right)(k)(j)\right) \wedge\right.\right. \\
& \left.\left.\tau(e) \subseteq t_{r} \wedge k[R] j \wedge R(j)=t_{r}\right) \wedge \underline{\left.R(k) \ll t_{r}\right)}\right)
\end{aligned}
$$

To satisfy the presupposition of the marked clause - the first underlined formula — the reference time of the marked clause must be located immediately after the reference point of the input state $(R(i))$.

That is, when the marked clause is in the perfective aspect, the event it describes should be interpreted as taking place immediately after the event described by the closest preceding perfective clause. This is indeed the case.

$$
\begin{aligned}
& \text { a. Su=naatsi'i oona ma-hu puni-kati-hu. Isu natsi'i yaisi yaa } \\
& \text { NOM=boy DEM DEM-EMPH see-sit-PFV DEM.NOM boy PTC DEM } \\
& \text { huna-ggwa-tu kimma-hu-si=ggaisu ka=ti=ddoogga hidda-pini-hu. } \\
& \text { outside-LOC-LOC come-PFV-SEQ=PTC ACC=REFL=dog hug-STAT-PFV }
\end{aligned}
$$

'The boy saw him over there, sitting. The boy came outside and hugged his dog.' (prompted narrative, EM, BP25-2-t1, 39-40) 
b. [...]yaisi tiwao ka=ti=pia ti-patsa-kwai-tu mimia-u, ka=kutsu.

PTC also ACC $=\mathrm{REFL}=$ friend NSP-kill-LOC-LOC go.DL-PFV ACC $=$ COW

U-ba yaisi pipiti-u-gaa-si, yaisi usu tiwao idza pia owi

3SG-LOC PTC arrive.PL-PFV-MOT-SEQ PTC DEM.NOM also coyote self DEM manai-čaa.

do-MOT

' $[$... ] and also went to where their friend was killed, the cow. Having arrived

beside it, that Coyote, he went and took over.' (narrative, Thornes 2003:481)

The discourse in 103 was prompted using the same picture book as before. It depicts a boy who sees his dog from the window of his room and then goes out to pick him up. The marked clause of the clause chain describes the event of the boy coming outside, which immediately follows the event of him seeing his dog described by the preceding sentence. Similarly, in $103 \mathrm{p}$, the marked clause described the event of Coyote and the Porcupine arriving at where the Cow was killed, which takes place immediately after the event of their leaving.

We can also use Partee's test to see whether the marked clause in a clause chain like 101 is interpreted at the current reference point. The sequence of independent sentences in 104 a was judged infelicitous relative to the situation depicted in Figure 2, where the boy does not miss the frog when it starts to escape, only later after he wakes up.

a. $\quad \# \mathrm{Su}=$ pa' $\operatorname{mogo}$ wadzi-mia-huka. $\mathbf{S u}=$ naatsi'i o=yaa-hu.

NOM=frog hide-go-INCEP NOM=boy 3sG.ACC=miss-PFV

Intended: 'The frog started to escape. The boy missed his frog.' (elicitation, EM, BP43-6, 4:00)

[EM: “Tibunihusi, yaisi $o=y a a h u$. ['He wakes up and then he misses him']."]

b. \# $\mathbf{S u}=$ pa'mogo wadzi-mia-huka. $\mathbf{S u}=$ tiitsi-'yu naatsi'i

NOM=frog hide-go-INCEP NOM=little-NOM boy

o=yaa-hu-si, sita-hu.

3SG.ACC=miss-PFV-SEQ get.angry-PFV

Intended: 'The frog started to escape. The little boy missed his frog, and then he got angry.' (elicitation, EM, BP43-6, 6:45)

[EM: "Well I think he was sleep, you know, when the frog left, yeah. Then, when he woke up, then he missed him and he got mad."]

The parallel clause chain in $104 \mathrm{~b}$ is also bad. The event described by the marked clause must be interpreted as immediately after the event described by the preceding sentence.

Going back now to the presupposition introduced by the unmarked clause in 101 . As shown in 102, it requires that the reference time of the unmarked clause be located immediately after the then-current reference point $(R(k))$. Since the marked clause is in the perfective aspect, this is not the same as the reference point of the original input state $(R(i))$. It has been reset to the reference time of the marked clause. Consequently, the unmarked clause is interpreted as taking placing immediately after the marked clause. This is a stronger meaning than what is provided by the semantics of the sequential suffix, which only entails that the unmarked clause is temporally located somewhere after the marked clause.

Again, Partee's test shows that the unmarked clause is interpreted at the then-current reference point. Speakers judge 105 as infelicitous in the state of affairs depicted by Figure 2. 
(105) \# Su=tiitsi-'yu pa'mogo wadzi-mia-huka-si, su=naatsi'i o=yaa-hu.

NOM=little-NOM frog hide-go-INCEP-SEQ NOM=boy 3SG.ACC=miss-PFV

'The little frog started to escape, and then the boy missed him.' (elicitation, MS, BP53-3, 31:45)

[MS: “Isaya' $e$ ['Lie'... ]he missed him when he woke up.’]

This clause chain is infelicitous because the event described by the unmarked clause does not occur immediately after the event described by the marked clause. Just like an independent sentence (104a) or marked clause (104 $)$, the unmarked clause is interpreted relative to the reference point established by the preceding discourse.

\subsection{The temporal relations between marked clauses}

We can now go back to clause chains containing multiple marked clauses. The sequential suffix only entails a temporal relation between the marked and unmarked clauses. But in some discourses, like the one below, repeated from 75 , speakers identify temporal relations between marked clauses.

$$
\begin{aligned}
& \text { Nimmi puggu tinoo-ggi-si, } \quad \mathrm{u}=\text { hibi-ggi-si, } \\
& \text { 1PL.EXCL.NOM horse pack-APPL-SEQ } 3 \text { SG.ACC=drink-APPL-SEQ go-PFV }
\end{aligned}
$$

'We packed up the horses, and then we watered them, and then we took off.' (elicitation, EM, BP44-2, 14:20)

[MT: "What happened first?[...]" EM: "Pack the horses. Then you gave them water, and then you left."]

I propose that these arise from the general principles for the interpretation of narrative discourse in 87. The clause chain in 106 has the same forward moving interpretation as the parallel sequence of independent sentences in 77 .

For concreteness, I assume that the clause chain in 106 has the structure below. The choice of bracketing is arbitrary and has no significant consequences for interpretation.

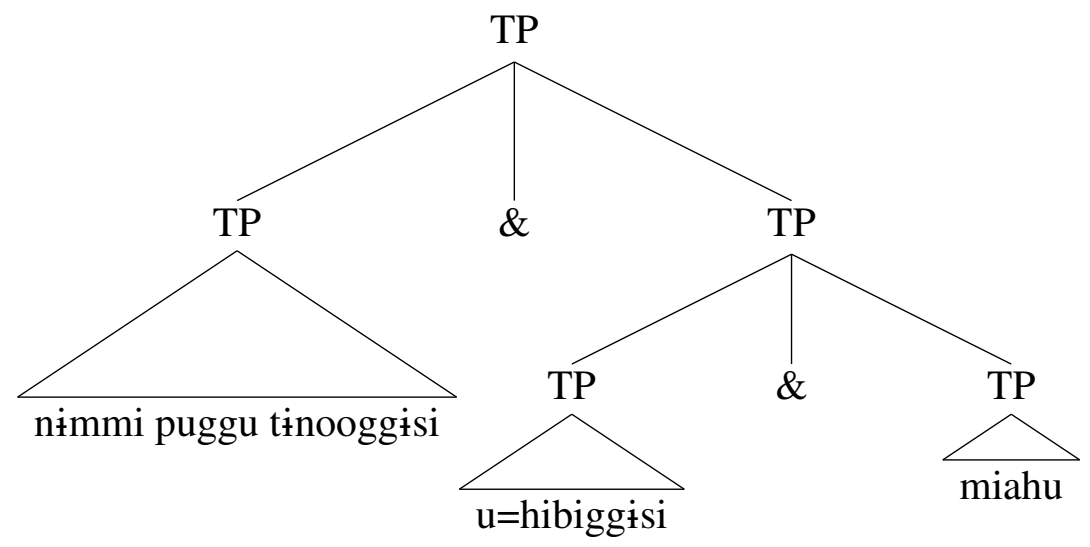

Without going through an entire semantic derivation, this sentence has the following final translation, after the Root Clause Rule applies. 
As before, the underspecified $\rho$ relation in the presupposition of each clause has been filled in. Since they are all in the perfective aspect, it is specified as immediate temporal precedence $(\ll)$.

In narratives, then, the marked clauses end up being temporally related to one another. As the first underlined formula shows, the reference time of the second marked clause must be located immediately after the then-current reference point $(R(k))$, which is the reference time of the first marked clause. There is, in addition, an additional temporal relation between the second marked clause and the unmarked clause, given by the second underlined formula. The reference time of the unmarked clause must be located immediately after the then-current reference point $(R(l))$, which is the reference time of the second marked clause. This forward moving interpretation for this clause chain goes beyond its entailments.

\subsection{When the marked clause follows}

Finally, we should look at how clause chains are interpreted in discourse when the marked clause follows the unmarked clause. As expected, in narratives, the presupposition of the unmarked clause relates its reference time to the current reference point according to the principles in 87 .

$$
\begin{aligned}
& \mathrm{Su}=\text { naatsi' } \mathrm{i}=\text { bino'o } \mathrm{ka}=\mathrm{t} \mathrm{t}=\mathrm{ddoogga} \text { haa-na, kuyaa o=ddaya-ggwine-hu } \\
& \text { NOM=boy=PTC } \quad \mathrm{ACC}=\mathrm{REFL}=\text { dog scold-SIM far } \quad \text { 3SG.ACC=send-MOT-PFV }
\end{aligned}
$$

tabbu'a. Yaisi ka=ggwitu'a tiggwisu ti=tsoti'a ddiggwa'ni mani-kati, yaa appear PTC ACC=pail still REFL=hat look.like do-sit.IMPF there paa'a-we kati-na.

water-LOC sit-SIM

'The boy is scolding his dog, and it looks like he sends him away. He still has the pail on his head that looks like a hat, while sitting in the water.' (prompted narrative, MS, BP24-1-t3, 41-42)

$$
\begin{aligned}
& \text { Su=ddoogga=bino'o yaa ika tibbi-ma yaa-na'ona-ba-ti mia-hu. Yaisi } \\
& \text { NOM=dog=PTC there DEM.ACC rock-LOC there-LOC-LOC-LOC go-PFV PTC } \\
& \text { yaa su=hibbi tihidda mia-hu, umi-ma sie-hu-si. } \\
& \text { there NOM=thing deer go-PFV 2/3PL.ACC-LOC get.scared-PFV-SEQ }
\end{aligned}
$$

'The dog went around the rock. The deer left because it got scared of them.' (prompted narrative, EM, BP25-2-t1, 93-95)

In 109 , repeated from 67 above, the unmarked clause describes the state of the boy continuing to have a bucket on his head. This includes the event described by the closest preceding perfective clause in which the boy sends the dog away. Similarly, in 110 , repeated from 68a above, the marked clause describes the event of the deer leaving. This is interpreted as taking place immediately after the event of the dog going around the rock described by the closest preceding clause in the perfective aspect. 
What about the presupposition of the marked clause in these chains? For the marked clause with the sequential suffix in 110 , the $\rho$ relation cannot be specified according to the principles for narratives in 87 . To see why, consider the final translation of this sentence.

$$
\begin{aligned}
& \lambda i \lambda j \exists k\left(\left(\exists e\left(\text { go }(\text { the-deer })(e)(i)(k) \wedge \neg \exists e^{\prime}\left(e \subset e^{\prime} \wedge \text { go (the-deer }\right)\left(e^{\prime}\right)(i)(k)\right) \wedge \tau(e) \subseteq t_{r} \wedge i[R] k \wedge R(k)=t_{r}\right) \wedge\right. \\
& \left.R(i) \ll t_{r}\right) \wedge \\
& \exists t^{\prime}\left(\exists e(\text { get-scared (the-deer })(e)(k)(j) \wedge \neg \exists e^{\prime}\left(e \subset e^{\prime} \wedge \text { get-scared (the-deer }\right)\left(e^{\prime}\right)(k)(j)\right) \wedge \tau(e) \subseteq t^{\prime} \wedge \\
& \left.\left.\left.k[R] j \wedge R(k)=t^{\prime}\right) \wedge t^{\prime}<t_{r} \wedge \rho\left(R(k), t^{\prime}\right)\right)\right)
\end{aligned}
$$

If the $\rho$ relation in the marked clause (the second underlined formula) were filled in with the immediate temporal precedence relation $(\ll)$, this would result in a contradiction. The sequential suffix entails that the reference time of the marked clause precedes the reference time of the unmarked clause.

But as we have already seen, not every sequence of sentences is a narrative. When one sentence serves as the explanation for another sentence, they receive a different temporal interpretation, e.g. Max fell. John pushed him. This is, I propose, how the marked clause in 110 is understood. As reflected in the translation, the deer's getting scared is the reason it leaves. The $\rho$ relation in the marked clause can consequently be specified as the inverse temporal relation, i.e. $R(k)>t^{\prime}$. This is compatible with the meaning of the sequential suffix, which entails that the marked clause temporally precedes the unmarked clause. I hypothesize that speakers might choose to order the marked clause after the unmarked clause for precisely this reason. If it contains the sequential suffix, the clause chain is not compatible with default narrative progression. It can thus be used to invite their interlocutor to infer a different rhetorical relation between the clauses.

\section{Conclusion and future prospects}

The temporal interpretation of clause chaining in Northern Paiute has, I propose, two meaning components. On the one hand, there is verbal morphology conveying relative tense - the simultaneous and sequential suffixes - which entails a temporal relation between each marked clause in a chain and the unmarked clause. On the other hand, this is enriched by principles for the interpretation of clause chaining in narrative discourse, giving rise to a 'forward moving' temporal interpretation across all the clauses in a chain.

This is a perhaps unpleasing division of labor. The principles for narrative progression are needed independently, so only the semantic component of clause chaining could possibly be eliminated. But it, too, is necessary, because a marked clause always bears the same temporal relation to the unmarked clause regardless of whether it precedes or follows it. This linear order insensitive component of meaning, I have argued, is derived through semantic binding of the relative tense inside the marked clause. In contrast, the temporal relations between marked clauses are sensitive to linear order.

We probably cannot, as Foley $(2010: 48)$ points out, "[... ]assume that clause chaining always corresponds to the same types of structures across languages." I have argued that clause chaining in Northern Paiute has a coordination structure. But in Choctaw and several other North American languages, it is likely that clause chaining has a subordination structure in which the marked clause is adjoined to the unmarked clause (Finer 1985, Broadwell 1997, 2006). Nonetheless, there are striking resemblances in the superficial form of clause chaining across a number of genetically unrelated and geographically distinct languages. 
Notably, Longacre (2007:398-417) observes that many languages indicate formally on the marked clause whether it temporally overlaps or precedes the unmarked clause. Of course, in Northern Paiute, this is exactly what the simultaneous and sequential suffixes do, which I have proposed are relative present and past tenses, respectively. Extending this analysis to comparable morphemes in other languages may allow us to account for this crosslinguistically uniform property of clause chaining, while still leaving room for variation in its syntax.

In Northern Paiute, the simultaneous and sequential suffixes can be abstracted over in a coordination structure only because the language is tenseless. In a language with absolute tense, it should instead be possible for clause chaining to have a subordination structure, as shown schematically below.

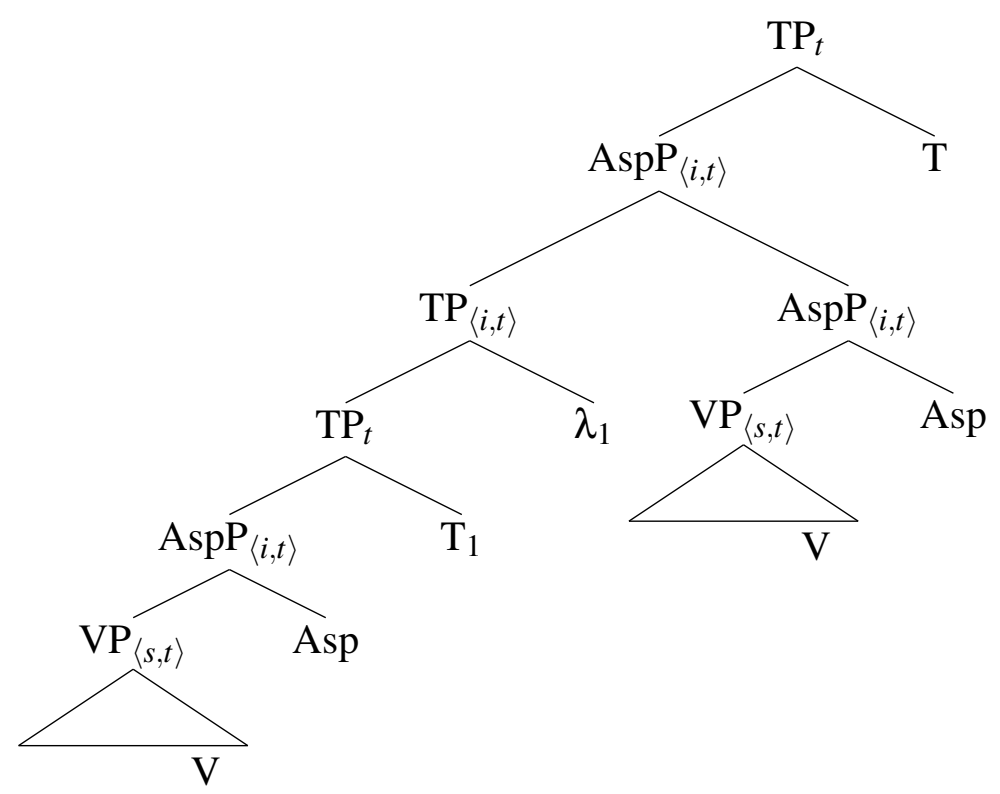

The relative tense inside the (subordinate) marked clause is abstracted over. The resulting property of time intervals can then be combined with the (main) unmarked clause by set intersection, or Predicate Modification, as long as it is adjoined below T. This is in some ways like the semantic composition of a temporal adjunct clause (see, for instance, von Stechow and Grønn 2013:314).

It seems that a particularly fruitful place to start investigating crosslinguistic variation in the syntax of clause chaining would be other Numic languages, such as Mono, or even more distantly related Uto-Aztecan languages. Like Northern Paiute, many of them have a clause chaining construction that formally marks a distinction between temporal simultaneity and temporal sequence (Langacker 1977:189-191). But they often mark absolute tense, so that the same compositional mechanism would not be available. Clause chaining in these languages might end up having a very different syntax, possibly one along the lines of the structure above. Only further research will tell.

\section{Appendix: On deverbal nominalization}

There are three arguments that the simultaneous suffix is distinct from a homophonous deverbal nominalizer, whose syntax and semantics I have discussed elsewhere (Toosarvandani 2011, to appear). 
First, the subject of a nominalization created by $-n a$ must be realized overtly. A weather verb, such as tiiggwa 'snow', normally takes no subject at all (113). But in the corresponding nominalization, an expletive — the fourth person clitic — is obligatory (114a).

Tịggwa-winni.

snow-PROG

'It's snowing.' (elicitation, MS, BP32-4-s, 13)
a. Nii $\quad *(\mathbf{a}=)$ ddiiggwa-winni-na punni.
1SG.NOM 4.GEN=Snow-PROG-NMLZ see.IMPF

'I see it snowing.' (elicitation, EM, BP37-3, 1:14:26)

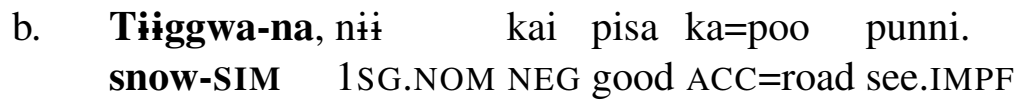

'When it is snowing, I don't see the road well.' (elicitation, MS, BP32-4-s, 1)

In contrast, the subject of the marked clause in a clause chain is frequently not overt (114p).

Second, the subject of the nominalization bears the genitive case $(114 \mathrm{~b})$, never the nominative case $(115 \mathrm{a})$.

a. * Nii saa-na ne-hu.

1SG.NOM cook-NMLZ burn-PFV

Intended: 'What I was cooking burned.' (elicitation, EM, BP43-2, 11:14)

b. Nii haki'i-na, nabagi'a.

1SG.NOM hiccough-SIM bathe.IMPF

'While I was hiccoughing, I swam.' (elicitation, MS, BP31-5-s, 5)

In contrast, the subject of the marked clause can bear nominative case (115b).

Third, as I discuss in Section 2.2, the simultaneous suffix imposes a number of restrictions on the aktionsart of the verb. For instance, it is completely impossible with achievements (116a), and it forces an iterative interpretation with semelfactives $(116 \mathrm{~b})$.

a. * Su=nana mia-na, hubiatu.

NOM=man go-SIM sing.IMPF

Intended: 'When the man was leaving, he was singing.' (elicitation, EM, BP48-5, 21:08)

b. $\quad$ Su=naatsi'i huni-na, nabagi'a.

NOM=boy fart-SIM bathe.IMPF

'While the boy is farting, he is taking a bath.' (elicitation, EM and MS, BP49-5, $1: 36: 37)$

[MS: "Probably make couple bubbles." MT: "Could it have been more than once?" MS: "Yeah, it can be more than one." EM: "Yeah."]

a. Su=mogo'ni i=mia-na punni-'yu.

NOM=woman 1SG.GEN=go-SIM see.IMPF-IMPF

'The woman sees me leaving.' (elicitation, EM, BP49-3-s, 4) 
b. Su=mogo'ni i=huni-na naka.

NOM=woman 1SG.GEN=fart-NMLZ hear

'The woman heard me fart.' (elicitation, EM, BP48-6, 42:33)

[EM: “That's just once."]

In contrast, the homophonous nominalizer is compatible with achievements $(117 \mathrm{a})$ and coerces no iterative interpretation with semelfactives $117 \mathrm{~b})$.

\section{References}

Abusch, Dorit. 1997. Sequence of tense and temporal de re. Linguistics and Philosophy 20:1-50. Asher, Nicholas and Alex Lascarides. 2003. Logics of conversation. Cambridge: Cambridge University Press.

Babel, Molly, Andrew Garrett, Michael J. Houser and Maziar Toosarvandani. 2013. Descent and diffusion in language diversification: A study of Western Numic dialectology. International Journal of American Linguistics 79:445-489.

Babel, Molly, Michael J. Houser and Maziar Toosarvandani. 2012. Mono Lake Northern Paiute. Journal of the International Phonetic Association 42:233-243.

Bar-Lev, Zev and Arthur Palacas. 1980. Semantic command over pragmatic priority. Lingua 51:137-146.

Barentsen, Adrian. 1996. Shifting points of orientation in Modern Russian. In Reported speech: Forms and functions of the verb, eds. Theo Janssen and Wim van der Wurff, 15-55. Amsterdam: John Benjamins.

Bittner, Maria. 2001. Surface composition as bridging. Journal of Semantics 18:127-177.

Bittner, Maria. 2005. Future discourse in a tenseless language. Journal of Semantics 22:339-387.

Bittner, Maria. 2008. Aspectual universals of temporal anaphora. In Theoretical and crosslinguistic approaches to the semantics of aspect, ed. Susan Rothstein, 349-385. Amsterdam: John Benjamins.

Bittner, Maria. 2011. Time and modality without tense or modals. In Tense across languages, eds. Renate Musan and Monika Rathert, 147-188. Berlin: Walter de Gruyer.

Bittner, Maria. 2014. Temporality: Universals and variation. Malden, MA: Wiley Blackwell.

Bohnemeyer, Jürgen. 2002. The grammar of time reference in Yukatek Maya. Munich: Lincom.

Bohnemeyer, Jürgen. To appear. Aspect vs. relative tense: The case reopened. Natural Language and Linguistic Theory .

Broadwell, George Aaron. 1997. Binding theory and switch-reference. In Atomism and binding, eds. Hans Bennis, Pierre Pica, and Johan Rooryck, 31-49. Dordrecht: Foris.

Broadwell, George Aaron. 2006. A Choctaw reference grammar. Lincoln: University of Nebraska Press.

Bybee, Joan, Revere Perkins and William Pagliuca. 1994. The evolution of grammar: Tense, aspect, and modality in the languages of the world. Chicago: University of Chicago Press.

Comrie, Bernard. 1985. Tense. Cambridge: Cambridge University Press.

Cover, Rebecca and Judith Tonhauser. To appear. Theories of meaning in the field: Temporal and aspectual reference. In Methodologies in semantic fieldwork, eds. Ryan Bochnak and Lisa Matthewson. Oxford: Oxford University Press. 
Dowty, David. 1977. Towards a semantic analysis of verb aspect and the English 'imperfective progressive'. Linguistics and Philosophy 1:45-78.

Dowty, David. 1979. Word meaning and Montague grammar. Dordrecht: Kluwer.

Dowty, David. 1986. The effects of aspectual class on the temporal structure of discourse. Linguistics and Philosophy 9:37-61.

Finer, Daniel L. 1985. The syntax of switch-reference. Linguistic Inquiry 16:35-55.

Foley, William and Robert D. Van Valin, Jr. 1984. Functional syntax and universal grammar. Cambridge: Cambridge University Press.

Foley, William A. 2010. Clause linkage and nexus in Papuan languages. In Clause linking and clause hierarchy, ed. Isabelle Bril, 27-50. Amsterdam: John Benjamins.

Golla, Victor. 2011. California Indian languages. Berkeley: University of California Press.

Gómez Txurruka, Isabel. 2003. The natural language conjunction and. Linguistics and Philosophy 26:255-285.

Groenendijk, Jeroen and Martin Stokhof. 1991. Dynamic predicate logic. Linguistics and Philosophy 14:39-100.

Haspelmath, Martin. 2004. Coordinating constructions: An overview. In Coordinating constructions, ed. Martin Haspelmath, 3-39. Amsterdam: Benjamins.

Hatav, Galia. 2010. Relative and absolute tense interpretation in Modern Hebrew. Hebrew Studies 51:261-285.

Heim, Irene and Angelika Kratzer. 1998. Semantics in Generative Grammar. Oxford: Blackwell.

Hinrichs, Erhard. 1986. Temporal anaphora in discourses of English. Linguistics and Philosophy 9:63-82.

Hobbs, Jerry R. 1979. Coherence and coreference. Cognitive Science 3:67-90.

Hobbs, Jerry R., Mark E. Stickel, Douglas E. Appelt and Paul Martin. 1993. Interpretation as abduction. Artifical Intelligence 63:69-142.

Huddleston, Rodney and Geoffrey K. Pullum, eds. 2002. The Cambridge grammar of the English language. Cambridge: Cambridge University Press.

Kamp, Hans, Josef van Genabith and Uwe Reyle. 2011. Discourse Representation Theory. In Handbook of philosophical logic, eds. Dov M. Gabbay and Franz Guenthner, volume 15, 125394. Dordrecht: Springer, 2nd edition.

Kamp, Hans and Uwe Reyle. 1993. From discourse to logic: Introduction to modeltheoretic semantics of natural language, formal logic, and Discourse Representation Theory. Dordrecht: Kluwer Academic Publishers.

Kamp, Hans and Christian Rohrer. 1983. Tense in texts. In Meaning, use, and interpretation of language, eds. Rainer Bäuerle, Christoph Schwarze, and Arnim von Stechow, 250-269. Berlin: Mouton de Gruyter.

Kehler, Andrew. 2002. Coherence, reference, and the theory of grammar. Stanford, CA: CSLI.

Klein, Wolfgang. 1994. Time in language. London: Routledge.

Koster, Jan. 1975. Dutch as an SOV language. Linguistic Analysis 1:111-136.

Kratzer, Angelika. 1998. More structural analogies between pronouns and tense. Semantics and Linguistic Theory (SALT) 8:92-110.

Laka, Itziar. 1990. Negation in syntax: On the nature of functional categories and projections. Ph.D. Dissertation, Massachusetts Institute of Technology.

Lamb, Sydney M. 1957. Mono grammar. Ph.D. Dissertation, University of California, Berkeley.

Landman, Fred. 1992. The progressive. Natural Language Semantics 1:1-32. 
Langacker, Ronald W. 1977. An overview of Uto-Aztecan grammar. In Studies in Uto-Aztecan grammar, ed. Ronald W. Langacker, volume 1, 1-199. Dallas, TX: Summer Institute of Linguistics and the University of Texas.

Lascarides, Alex and Nicholas Asher. 1993. Temporal interpretation, discourse relations, and commonsense entailment. Linguistics and Philosophy 16:437-493.

Link, Godehard. 1987. Algebraic semantics for event structures. Amsterdam Colloquium 7:243262.

Longacre, Robert E. 2007. Sentences as combinations of clauses. In Language typology and syntactic description, ed. Timothy Shopen, volume 2, 372-420. Cambridge: Cambridge University Press, 2nd edition.

Matthewson, Lisa. 2006. Temporal semantics in a superficially tenseless language. Linguistics and Philosophy 29:673-713.

McKenzie, Andrew. 2012. The role of contextual restriction in reference-tracking. Ph.D. Dissertation, University of Massachusetts, Amherst.

Moens, Marc and Mark Steedman. 1988. Temporal ontology and temporal reference. Computational Linguistics 14:15-28.

Muskens, Reinhard. 1995. Tense and the logic of change. In Lexical knowledge in the organization of language, eds. Urs Egli, Peter E. Pause, Christoph Schwarze, Armin von Stechow, and Götz Wienold, 147-183. Amsterdam: John Benjamins.

Muskens, Reinhard. 1996. Combining Montague Semantics and Discourse Representation. Linguistics and Philosophy 19:143-186.

Nonato, Rafael. 2013. Clause chaining is asymmetric vP coordination. Ms., Massachusetts Institute of Technology.

Ogihara, Toshiyuki. 1994. Adverbs of quantification and sequence-of-tense phenomena. Semantics and Linguistic Theory (SALT) 4:251-267.

Ogihara, Toshiyuki. 1995. The semantics of tense in embedded clauses. Linguistic Inquiry 26:663679.

Ogihara, Toshiyuki. 1996. Tense, attitudes, and scope. Dordrecht: Kluwer.

Ogihara, Toshiyuki and Yael Sharvit. 2012. Embedded tenses. In The Oxford handbook of tense and aspect, ed. Robert I. Binnick, 638-668. Oxford: Oxford University Press.

Pancheva, Roumyana. 2003. The aspectual makeup of perfect participles and the interpretation of the perfect. In Perfect explorations, eds. Artemis Alexiadou, Monika Rathert, and Arnim von Stechow, 277-306. Berlin: Mouton de Gruyter.

Partee, Barbara H. 1973. Some structural analogies between tenses and pronouns in English. Journal of Philosophy 70:601-609.

Partee, Barbara H. 1984. Nominal and temporal anaphora. Linguistics and Philosophy 7:243-286.

Portner, Paul. 1998. The progressive in modal semantics. Language 74:760-787.

Reichenbach, Hans. 1947. Elements of symbolic logic. Berkeley, CA: University of California Press.

Roberts, John R. 1988. Amele switch-reference and the theory of grammar. Linguistic Inquiry 19:45-63.

Rooth, Mats and Barbara Partee. 1982. Conjunction, type ambiguity, and wide scope "or". West Coast Conference on Formal Linguistics (WCCFL) 1:353-362.

Ross, John Robert. 1967. Constraints on variables in syntax. Ph.D. Dissertation, Massachusetts Institute of Technology. 
Schaden, Gerhard. 2011. Introducing the present perfective puzzle. In From now to eternity, eds. Jesse Mortelmans, Tanja Mortelmans, and Walter De Mulder, volume 22 of Cahiers Chronos, 105-122. Amsterdam: Rodopi.

Schlenker, Philippe. 2003. A plea for monsters. Linguistics and Philosophy 26:29-120.

Shaer, Benjamin. 2003. Toward the tenseless analysis of a tenseless language. Semantics of Underrepresented Languages in the Americas (SULA) 2:139-156.

Smith, Carlota S. 1997. The paramater of aspect. Dordrecht: Kluwer Academic Publishers, 2nd edition.

von Stechow, Arnim and Atle Grønn. 2013. Tense in adjuncts part 2: Temporal adverbial clauses. Language and Linguistics Compass 7:311-327.

Thornes, Tim. 2003. A Northern Paiute grammar with texts. Ph.D. Dissertation, University of Oregon.

Tonhauser, Judith. 2011. Temporal reference in Paraguayan Guaraní, a tenseless language. Linguistics and Philosophy 34:257-303.

Toosarvandani, Maziar. 2011. The role of nominalization in Northern Paiute relative clause formation. Workshop on Structure and Constituency in the Languages of the Americas (WSCLA) 16:151-165.

Toosarvandani, Maziar. To appear. Two types of deverbal nominalization in Northern Paiute. Language URL http://people.ucsc.edu/ mtoosarv/papers/two-types-deverbal-nominalization.pdf.

Webber, Bonnie Lynn. 1988. Tense as discourse anaphora. Computational Linguistics 14:61-73.

Wilhelm, Andrea. 2007. Telicity and durativity: A study of aspect in Dëne Sütiné (Chipewyan) and German. New York: Routledge.

University of California, Santa Cruz

Department of Linguistics

1156 High Street

Santa Cruz, CA 95064

mtoosarv@ucsc.edu

http://people.ucsc.edu/ mtoosarv/ 